Review

\title{
Coating-Based Quartz Crystal Microbalance Detection Methods of Environmentally Relevant Volatile Organic Compounds
}

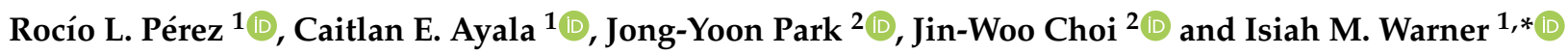 \\ 1 Department of Chemistry, Louisiana State University, Baton Rouge, LA 70803, USA; \\ rperez@lsu.edu (R.L.P.); ayala1@lsu.edu (C.E.A.) \\ 2 School of Electrical Engineering and Computer Science, Louisiana State University, \\ Baton Rouge, LA 70803, USA; jpar132@lsu.edu (J.-Y.P.); choijw@lsu.edu (J.-W.C.) \\ * Correspondence: iwarner@lsu.edu; Tel.: +1-225-578-2829
}

Citation: Pérez, R.L.; Ayala, C.E.; Park, J.-Y.; Choi, J.-W.; Warner, I.M. Coating-Based Quartz Crystal

Microbalance Detection Methods of Environmentally Relevant Volatile Organic Compounds. Chemosensors 2021, 9, 153. https://doi.org/ $10.3390 /$ chemosensors 9070153

Academic Editor: Salih Okur

Received: 24 May 2021

Accepted: 18 June 2021

Published: 24 June 2021

Publisher's Note: MDPI stays neutral with regard to jurisdictional claims in published maps and institutional affiliations.

Copyright: (c) 2021 by the authors. Licensee MDPI, Basel, Switzerland. This article is an open access article distributed under the terms and conditions of the Creative Commons Attribution (CC BY) license (https:/ / creativecommons.org/licenses/by/ $4.0 /)$.

\begin{abstract}
Volatile organic compounds (VOCs) that evaporate under standard atmospheric conditions are of growing concern. This is because it is well established that VOCs represent major contamination risks since release of these compounds into the atmosphere can contribute to global warming, and thus, can also be detrimental to the overall health of worldwide populations including plants, animals, and humans. Consequently, the detection, discrimination, and quantification of VOCs have become highly relevant areas of research over the past few decades. One method that has been and continues to be creatively developed for analyses of VOCs is the Quartz Crystal Microbalance (QCM). In this review, we summarize and analyze applications of QCM devices for the development of sensor arrays aimed at the detection of environmentally relevant VOCs. Herein, we also summarize applications of a variety of coatings, e.g., polymers, macrocycles, and ionic liquids that have been used and reported in the literature for surface modification in order to enhance sensing and selective detection of VOCs using quartz crystal resonators (QCRs) and thus QCM. In this review, we also summarize novel electronic systems that have been developed for improved QCM measurements.
\end{abstract}

Keywords: volatile organic compounds; quartz crystal microbalance; sensor arrays; coating materials; electronic systems

\section{Introduction}

Organic compounds containing carbon, along with at least one hydrogen, oxygen, chlorine, bromine, fluorine, sulfur, or nitrogen atom, evaporate at room temperature and present a certain reactivity in the atmosphere. These compounds are generally defined as volatile organic compounds (VOCs) by the U.S. Environmental Protection Agency (EPA) [1,2]. Depending on VOC boiling points, these types of compound will present different volatilities and could be classified according to their boiling point into very volatile organic compounds (VVOCs), volatile organic compounds (VOCs), and semi-volatile organic compounds (SVOCs) [2]. A wide variety of VOCs originated from several types of biogenic or natural sources, such as plants, animals, microbes, and volcanos [3-6], along with anthropogenic or artificial origins, like cleaning products, solvents, electronic, domestic, industrial, transport, among others [7-9]. As a result, the presence of VOCs in different locations, such as buildings or factories, waste water, tap water, or bacterial or fungi contamination in food samples [10-13], could indicate significant hazardous contaminations and/or health risks. The field of medicine has also begun to capitalize on VOC detection and determination with e-nose systems through an analysis of skin, breath, urine, blood, and other biosamples as potential non-invasive routes for the potential for diagnoses of illnesses [14-17]. Additionally, the presence of VOCs in breath could be indicative of certain diseases (diabetes, lung cancer, among others) [18-26]. For this reason, the detection and discrimination of VOCs for a wide variety of applications is of major interest.

Traditionally, gas chromatography (GC) is the most commonly employed technique for the detection and quantification of VOCs. GC has been coupled to different detectors, like 
mass spectrometer detector (MS) [27-29], flame ionization detector (FID) [30-33], ion mobility spectrometry (IMS) [34,35], and ion-trap/mass spectrometry detection (IT/MS) [36,37] to determine the presence of VOCs. However, this intricate technique requires expensive equipment as well as specialized personnel for operation. Moreover, different detectors present certain disadvantages, such as the destruction of a sample in the case of FID or low mass accuracy for IT/MS detection. Another widely employed technique for VOC detection is Fourier Transform Infrared spectroscopy (FT-IR), which has been employed for the detection of VOCs in water and solid samples $[38,39]$. The methodologies described above provide reliable and accurate results; however, the operations are performed off-line, which is associated with collection, pre-concentration, and often the chemical processing of the samples. Inevitably, these steps increase the time consumed during the analysis. For this reason, the development of sensor-based methods employing electrical systems based on the human nose, or electronic noses, for the detection of VOCs has gained interest in the scientific community in recent decades.

In the human nose, around 400 smell receptors are present, which are connected through nerves to the brain. When those receptors are exposed to a scent, each will produce a specific signal response. Finally, a combination of these signal responses will be sent to the brain, where processing and scent identification occurs. Due to the complexity of the human nose, these receptors are able to detect and distinguish over one trillion different odors [40,41]. Based on this mechanism, Krishna Persaud and George Dodd developed the concept of an electronic nose, or "e-nose," in 1982 [42,43]. Generally, an e-nose consists of a series of distinct chemical sensors that act as cross-reactive elements arranged in an array (Figure 1). Upon exposure to vapors, these sensors generate either a total or partial specific response pattern that is then evaluated through a pattern recognition system. This process will allow for the recognition of a single vapor or a mixture of vapors. Scientists have also explored and evaluated different types of statistical and mathematical tools for the differentiation and discrimination of these response patterns, such as linear regression algorithms, discriminant analysis (DA), principal component analysis (PCA), artificial neural networks (ANNs), etc. Figure 1 is a display of a schematic workflow of an e-nose system for several types of application.

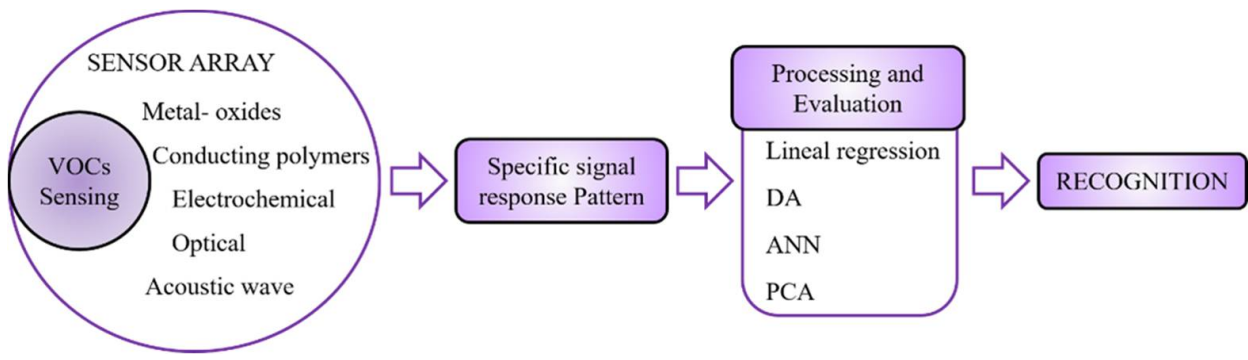

Figure 1. Schematic workflow of an e-nose system.

Different sensors arrays for gas sensing for several applications have been reported in the literature, such as metal-oxides [44-49], conductive polymers [50-54], electrochemical [55,56], optical [57-60], and acoustic wave sensors [61,62]. Each one of these chemical sensors have different detection mechanisms and present specific advantages and disadvantages. For example, in the case of conducting polymer vapor sensors, a high sensitivity was achieved with short response times; however, these types of sensors, in general, tend to be overloaded by analyte [63]. Thus, their lifetimes and reusability are limited. Metaloxides, on the other hand, present high sensitivity as they detect VOCs through oxidation or reduction; but require high operation temperatures, which leads to a high energy consumption. In this regard, acoustic wave sensors are based on the measurement of mass change adsorbed, and have the potential to solve these other problems mentioned above. This review will be focused on quartz crystal microbalance devices (QCM), an acoustic 
wave sensing system in which the mechanism of this type of sensor is based on elastic waves propagating through the substrate upon excitation from an appropriate voltage [64].

As a result of the yearly increase in the amount of anthropogenic VOCs that have been introduced into the atmosphere, another typical application of QCM devices is detection and discrimination of environmental concerning VOCs. These VOC emissions represent a major contamination risk for the environment and can have a significant detrimental effect on the health of plants, animals and humans. Other volatile compounds, such as organophosphates for example, are employed as pesticides, flame-retardants in polymers, electric appliances, aircraft and building materials [65-68]. Moreover, a great amount of cleaning products, like air fresheners, cleaners, furniture polisher, toilet products, laundry detergent, among others, introduce different types of VOCs [69-72]. In another respect, common VOCs like toluene, benzene, isomers of xylene, and ethylbenzene are frequently used in the production of paints and coatings, leather, rubber, and other synthetic material production that present risk factors upon acute or chronic exposure to high levels of each compound [73-75].

The mechanism of absorption/desorption of VOCs on the bare QCR surface has been explained in other works [76-79]. In this review, we describe the recent trends of theory and use of coating-based QCM measurement systems for environmentally relevant VOC detection. As many detection techniques have been developed, QCM has the advantage of a low limit of detection, along with others described in various sections below. Statistical analysis techniques based on the resultant data output are discussed to provide potential sensor arrays that may be obtained. We also describe the use of various coating materials to provide the selective detection of VOCs through the use of carbonaceous materials (i.e., graphene oxide, polymers, organic ionic materials).

Additionally, another aspect of the QCM devices that has to be taken into consideration is the electronic operation system that is employed to measure changes in frequency. Various research groups have focused on the development of electronic configurations of QCM devices to pursue the potential optimization of signal measurements through different electronic operation systems that, eventually, could present different sensitivities. In this review, we also summarize the electronic measurement systems currently employed for QCM systems.

\section{Quartz Crystal Microbalance Devices: Gravimetric and Non-Gravimetric Sensing}

A well-known and commonly used thickness shear mode (TMS) is the quartz crystal microbalance (QCM). This type of device is more sensitive to most studied VOCs, is inexpensive and presents rapid responses and portability, and can be employed in real time procedures, which is promising for the online detection of target compounds. Owing to these characteristics, an increase of interest from the scientific community in the use of QCM devices for sensing of VOCs has been reflected on the number of publications in the past two decades (Figure 2).

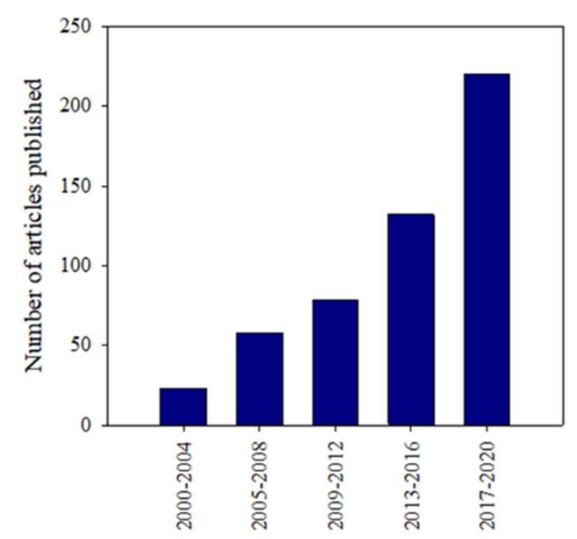

Figure 2. Number of publications in the last two decades from Science Direct website when keywords were: quartz crystal microbalance, sensors and VOCs. 
The working mechanism of a QCM is based on the piezoelectric effect. This effect was discovered in 1880 by the Curie brothers [80]. They found that when certain asymmetrical crystal structures, such as quartz or topaz, were submitted to a mechanical stress, a voltage proportional to this stress will be produced. In the opposite manner, when a voltage is applied to these types of crystalline materials, a mechanical deformation will be generated. Later, Sauerbrey demonstrated that when a voltage is applied in an AT-and BT-cut quartz crystal within two metal electrodes (Figure 3), the crystal oscillates in a specific frequency. These crystal are known as quartz crystal resonators (QCRs), and the wave generated on them is known as the resonance frequency [81].

(A)

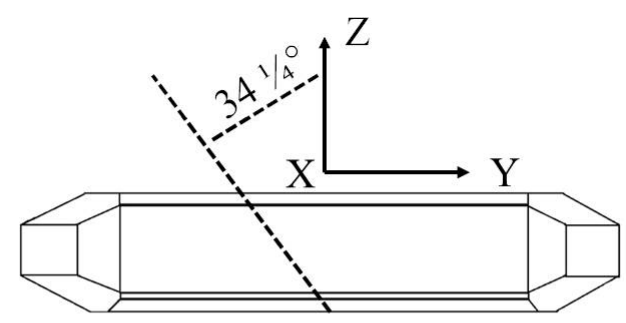

(B)
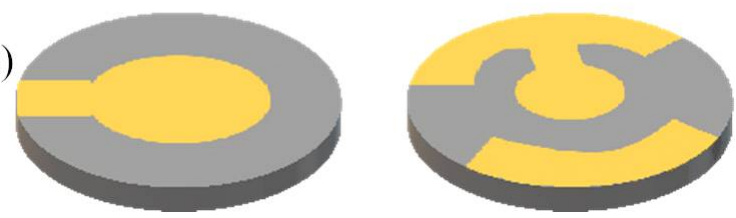

Figure 3. (A) AT-cut crystal scheme, and (B) QCR with gold electrodes scheme.

Depending on the thickness between the nodes and the antinodes of the crystal, the wave formed when a voltage is applied will have a specific wavelength. This relationship is given by the following Equation (1):

$$
f=\frac{c_{q}}{\lambda}=\frac{c_{q}}{2\left(d_{q}+d_{f}\right)}
$$

where $f$ is the frequency, $c_{q}$ is speed of sound, $\lambda$ is wavelength, $d_{q}$ is thickness of QCR, and $d_{f}$ is the film thickness [82]. According to this Equation, an increase on the thickness of the QCR by the addition of any material in the QCR surface will be reflected in a decrease of resonance frequency. From this finding, Sauerbrey was able to deduce that the QCM could be employed as a mass detector and found the relationship between the change in resonance frequency to the change on mass [81]. This Equation is known as the Sauerbrey Equation (2):

$$
\Delta f=-\frac{n}{c} * \Delta m=-\frac{n}{c} \rho_{f} t_{f}
$$

where $\Delta f$ is change in frequency, $n$ is harmonic number, $c$ is mass sensitivity, $\rho_{f}$ is density of the film, and $t_{f}$ is film thickness [81].

Along with the fundamental resonance frequency, the QCR could generate higher resonance frequencies that are known as harmonics. These harmonics can only be generated in odd multiples of the fundamental one due to the nodes of the wave inside the crystal [83]. As a result, the fundamental frequency, or the first harmonic, correspond to the wave that has only one node inside the crystal. A wave that has three nodes inside the crystal represents the third harmonic. Figure 4 is a display of these harmonics inside the QCR. 


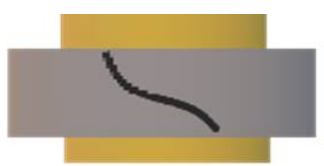

(A)

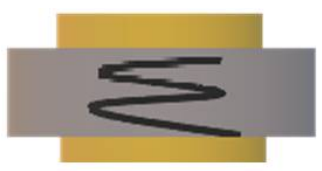

(B)

Figure 4. Representation of wave behavior inside the QCR for (A) fundamental frequency, and (B) the third harmonic.

As mentioned previously, QCM devices have been traditionally employed as gravimetric sensing devices, as defined by the Sauerbrey Equation (2). As a result, any mass deposition on the QCR surface should result in a decreased frequency. This effect is known as "ideal behavior," which is only observed with rigid, thin, and uniform film coatings. A deviation in this ideal behavior might be observed if the film does not meet these characteristics. Deviations from this behavior can occur with films that are thick, soft, or viscous. As a result, changes in frequency responses will depend on the resonance, thickness, and viscoelasticity of each film. In some cases, these resultant responses have positive changes in frequency [84-86]. For this reason, these type of films could be employed for the development of QCM-based sensor arrays. In this case, the QCM device could be used as a non-gravimetric sensing technique.

\section{Commonly Employed Coating Materials for QCM-Based Sensors}

During the past two decades, a great variety of materials have been employed by the scientific community as coating materials applied on the surface of QCR to target a specific or a related group of VOCs. Within the published works, we could find a broad diversity of materials like carbon-nanotubes, graphene oxide, conductive polymers, ionic liquids (ILs), etc., in which exposure to VOCs provided different mechanisms of interaction with the coating surface (Figure 5). These types of materials have been chosen due to their absorption and sensitivity properties. Herein, we summarize several research works where different coating materials have been employed for the development of QCM-based sensors.

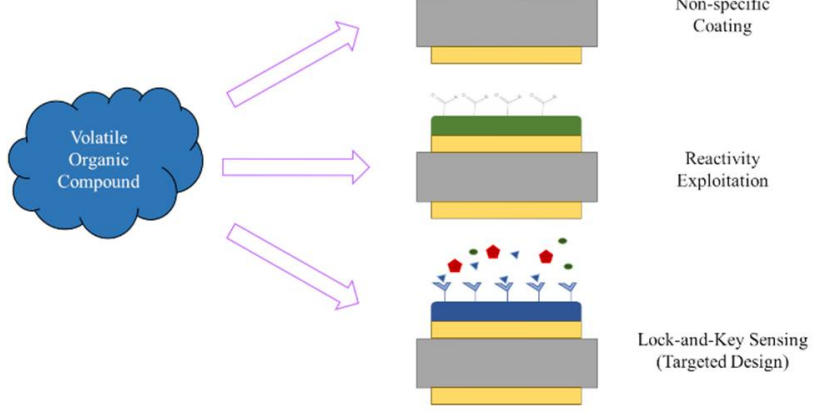

Figure 5. Selectivity mechanisms of various coatings commonly employed in QCM methods.

\subsection{Polymer-Based Coating Materials}

Polymer materials have been used as coating materials of QCM devices due to their relative ease of synthesis and viscoelastic properties. Different deposition techniques allow for a variety of structural formations on the QCR surface as well. Researchers are able to achieve a high conductivity and an increased surface area, as well as selectivity according to the functional groups present in the polymers.

Detection of trace levels of p-xylene has been achieved through QCRs coated with poly(4-vynilbenzyl chloride) (PVBC) and poly(4-vinylbenzyl chloride-co-methyl methacrylate) (PVBC-co-MMA) [87]. In this work, polymers were being synthesized through a free radical polymerization reaction and were then dissolved in chloroform coated on the QCR 
through spin-coating to form thin films. The responses of both sensors were evaluated towards p-xylene and other VOCs (toluene, butyl acetate and, 1-butanol). PVBC-coated QCR showed a greater sensitivity towards p-xylene in comparison to the other VOCs studied. However, the introduction of MMA monomer in the polymer increased this sensitivity significantly. For this reason, the authors studied different thicknesses of PVBC-co-MMA coatings. An increase in the thickness of the polymer coating showed a decrease in the sensitivity that could be possible for the adsorption of less p-xylene by the coating material. Optimal conditions for p-xylene sensing achieved an LOD of $54 \mathrm{ppm}$.

In another report, Fan et al. were able to detect 1-butanol with high selectivity by coating their QCR with poly(2-hydroxyethyl methacrylate-co-methylacrylate) (P(HEMA-co-MA)) copolymer [88]. The sensor response of P(HEMA-co-MA) was tested against toluene, $\mathrm{p}$-xylene, butyl acetate and 1-butanol. This thin film of copolymer shows more sensitivity towards 1-butanol than other tested VOCs. Moreover, the P(HEMA-co-MA) thin film responses were evaluated when it was exposed to other alcohols, such as methanol, ethanol, 1-propanol, and isopropanol. The change in frequency obtained when the copolymer was in contact and these alcohols were not significant in comparison to the change obtained with 1-butanol. This indicated that this sensor is more sensitive to the detection of 1-butanol, reaching an LOD of $72 \mathrm{ppm}$.

In several other works, Rianjanu and coworkers evaluated different coating forms of polyvinyl acetate (PVAc) for sensitivity for a variety of alcohol analytes. In one report, PVAc nanofibers were formed via electrospinning for small chain primary alcohol sensitivity among methanol, ethanol, n-propanol, n-butanol, and n-pentanol [89]. It was determined that nanofibers were most sensitive to $\mathrm{n}$-pentanol vapors with $0.023 \mathrm{mg} / \mathrm{L}$ LOD. This was hypothesized by the authors to be a result of surface interactions of hydrogen bonds from alcohol groups along with hydrophobic interactions promoted by the length of the alkyl chains between ketone and hydrophobic regions of polymer chains, respectively. Another investigation was performed to examine various isomers of butanol, such as n-butanol, 2-methylpropan-1-ol, butan-2-ol, and 2-methylpropan-2-ol [90]. In this report, electrospun PVAc nanofibers were most sensitive to n-butanol and 2-methylpropan1-ol, with LODs of 0.05 and $0.07 \mathrm{mg} / \mathrm{L}$, which also provides higher propensities for surface interactions of the alkyl side chain with the hydrophobic regions of PVAc fibers. To investigate the stability of PVAc nanofibers versus thin film mats deposited by spin-coating, another investigation was reported and confirmed the necessity of a high surface area of nanofibers for prolonged n-butanol sensitivity [91]. Thin film stability was determined to decrease by approximately $7 \%$ frequency shifts over repeated use as a result of low porosity, which was not observed in nanofibers and demonstrated prolonged stability. In this respect, this group was able to continue with other investigations and show the utility of electrospun PVAc, a relatively inexpensive polymer, for a multitude of VOC sensitivities [92-96].

Carbohydrate polymers, such as chitosan (CS), are another group of naturally occurring biosensors that have recently been employed for composites fabrication and QCR coatings for VOCs. Polyaniline (PANI) and CS nanofibers were synthesized by Ayad et al. and employed as a coating material to determine amines vapors [97]. Due to the presence of hydrogen bond capable hydroxyl and amine groups on the CS, the authors targeted the detection of amines and alcohols with these nanofibers. A good linear relationship was found for methylamine, dimethylamine and ethanol employing this composite. In another work, Triyana and coworkers used l-cysteine and glutaraldehyde to anchor CS to QCRs and analyze responses to n-amyl alcohol, isoamyl alcohol, isopropanol, and ethanol [98]. Linear responses were observed for each analyte, with the highest sensitivity of $4.4(\mathrm{~Hz} \cdot \mathrm{mg}) / \mathrm{L}$ determined for n-amyl alcohol with an LOD of $0.25 \mathrm{mg} / \mathrm{L}$. Nughroho et al. employed cellulose acetate (CA) nanofibers overlaid with CS to provide nucleophilic surface interactions from nucleophilic amine groups of CS to electrophilic carbonyl groups of acetic anhydride (AA) vapor [99]. These authors determined that this method of carbohydrate QCR coating functioned for AA vapor detection with an LOD of $5 \mathrm{ppm}$ and an LOQ of 16 ppm, respectively [100]. 
Additionally, the synthesis of molecular imprinted polymers (MIP) has been developed for the sensing of different VOCs in other studies [101-103]. These sensory systems are fabricated using a desired analyte as a template, and once these templates are removed after polymer synthesis, and QCRs coated, the resultant sensors are highly specific for VOCs. Hussain et al. reported the quantification of formaldehyde through nanoparticles and films of MIP reaching lower concentrations as $500 \mathrm{ppb}$. The high selectivity reached by the MIP is reflected in the lower LOD obtained in this study [102]. Chen and coworkers used this strategy to form an MIP-hexanal sensor since it is a VOC that is often found as a biomarker in agricultural industries, and as a marker in food quality control. Methacrylic acid and ethylene glycol dimethacrylate were polymerized with initiator $2,2^{\prime}$-azobis(isobutyronitrile) (AIBN) in the presence of hexanal. Soxhlet extraction was employed to remove the template, and MIPs were sonicated with silica nanoparticles and coated onto clean QCRs [104]. After QCR coating and analysis among other VOCs, coated QCRs were found to be sensitive to hexanal from 1 to $80 \mathrm{ppm}$, and they showed selectivity to this VOC in high relative humidities and when exposed to structurally similar VOCs, octanal and nonanal.

In cases for VOCs that are structurally inert, MIP synthesis is more difficult as template inclusion may not be directly performed with these structures due to a lack of reactive functional groups. For compounds such as benzene, toluene, xylenes (BTX), or methyl ketones, scientists have employed structurally similar components for MIP templates. In one respect, Hwang and coworkers used phenol and acetoin as templates in an MIP synthesis with 1,4-divinyl benzene, 4-vinylpyridine, and AIBN for benzene and isopropyl methyl ketone detection [103]. After synthesis, templates were removed via extraction several times with methanol. Coating QCR surfaces was performed byspin-coating a suspension of MIPs in methanol. In this work, the authors established the sensitivity for desired analytes, and determined that Langmuir isotherms were linear up to $200 \mathrm{~Pa}$ of each analyte. From this information, the authors also investigated adsorption-based sensor capabilities for binary VOC mixtures, and established 91.5\% accuracy and 91.6\% accuracy with a single component (Markham-Benton) and multi-component (IAS) partial pressure models, respectively. In another work, BTX were chosen as desired analytes, and Banerjee and coworkers screened ten different templates containing different benzyl functional groups with styrene, divinylbenzene, tung oil, and benzoyl peroxide as the initiators [105] Ultimately, 1,2,3-trimethoxybenzene was determined to be the most sensitive MIP template for BTX quantification. In this report, QCR coating was performed with a prepolymer mixture, was heated and the template was removed by submersion of the coated QCR into ethanol. Benzene was found to provide highest MIP sensitivities, followed by toluene, $\mathrm{o}-, \mathrm{m}-$, then p-xylenes, with sensitivities between 1.645 to $2.605 \mathrm{~Hz}$ per ppm between 5 to $250 \mathrm{ppm}$. Limits of detection and quantification were determined to range from 0.99 to $1.36 \mathrm{ppm}$ and 2.99 to $4.13 \mathrm{ppm}$ (benzene to p-Xylene), respectively.

\section{Carbon-Based Coating Materials}

Carbon-based nanomaterials have been employed as coating materials for VOC sensing due to their high adsorptive and conductivity properties. Figure 6 is a display of the representation of the carbon-based coating materials commonly used. 
(A)

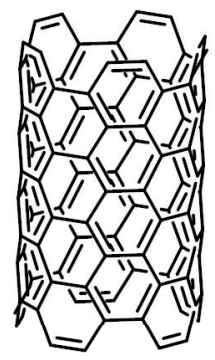

(B)

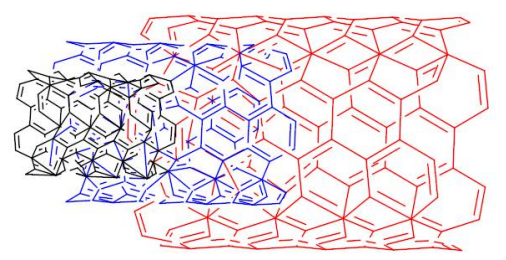

(C)

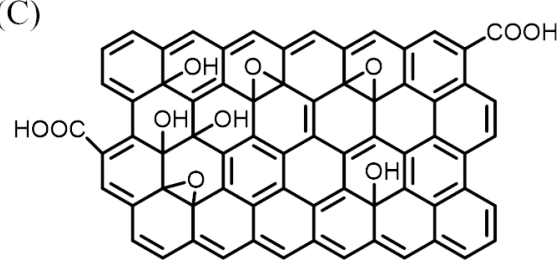

Figure 6. General structure of (A) single-wall carbon nanotubes (SWNTs), (B) multi-wall carbon nanotubes (MW-NTs), and (C) graphene oxide (GO).

For instance, single-wall carbon nanotubes (SWNTs) that present a particular cylindrical structure provide electronic and chemical properties that have been employed for the detection of vapors. Lu et al. employed SWNTs and its acidic ester and a sodium dodecyl sulfate modified version as coating sensor materials of two sensing platforms, a chemiresistor (CR) and QCM for sensing different VOCs. In this work, polar and non-polar VOCs were tested and the responses of each type of SWNT were evaluated. The authors noticed that modifications in the SWNTs created changes in the response patterns. The acidic SWNTs were more selective to polar VOCs, like butanol, where hydrogen bonding interactions could take place. Moreover, SDS-SWNTs demonstrated a higher mass adsorption in comparison with the rest of the SWNTs tested. These diverse responses obtained with the two sensing platforms when the naked SWNTs and modified SWNTs where employed as coating materials could be used as a highly sensitive hybrid array for the possible identification of VOCs [106]. Another group conducted research combining two types of sensing platforms using an optical fiber and QCM to develop a hybrid sensor array to obtain a high discrimination of tested VOCs. In this case, Consales et al. employed two types of coating a cadmium arachidate and others coated with SWNTs over cadmium. The responses of the QCM and fiber optic sensors in the presence of six VOCs (methanol, ethanol, isopropanol, acetone, ethylacetate, and toluene) were tested by the authors. In this work, they proved that the sensitivity of coated QCM sensors was improved when the sensors were coated with SWNTs and cadmium. The sensor response patterns obtained with these two platforms were analyzed with PCA and ANN algorithms for the discrimination of the studied VOCs. The combination of these responses produced significantly improved the sensitivity of this sensor [107].

In another report, Mañoso et al. investigated the responses of a QCR sensor that were modified through the application of different thickness of multi-wall carbon nanotubes (MWCNTs) [108]. In this work, the researchers removed the different areas of the gold electrode region in the QCR and replaced with the MWCNTs. Moreover, authors employed three different techniques (Triton X-100 with methanol and water, sodium dodecylsulfate in methanol, acetonitrile and toluene and the last was Triton X-100 in toluene) to attach the MWCNTs to the QCR electrode. These modifications were evaluated testing its responses to different VOCs, like benzene, xylenes, ethylbenzene, toluene, aldehydes and amines. The sensitivity to these VOCs was remarkably increased when the modified QCRs were employed. The lower limit of detections (LODs), as low as $0.01 \mathrm{mg} / \mathrm{L}$, were achieved when the QCRs were modified with MCNTs in the presence of Titron X-100 and toluene. 
Other investigations were focused on the use of graphene oxide (GO) as a sensing material on QCM techniques. For example, Quang et al. employed a novel technique to grow graphene oxide over a copper foil, covering the graphene oxide layer with a polymethyl methacrylate (PMMA) layer to remove the cooper foil, and later to transfer it over the QCR surface to finally remove the PMMA layer. Quang and coworkers demonstrated that the sensitivity towards, butanol, isopropanol, ethanol, and acetone was highly increased in comparison with the naked QCR electrode. Moreover, the authors observed a fast response-recovery behavior of the GO-coated QCR in comparison with other types of coatings published in the literature [109]. In another report, Zhang et al. developed a composite formed by GO combined with chitosan (CS) as a coating material of a QCR for the detection of low molecular weight amines [110]. The authors prepare the nanocomposite through the simple mixture of a CS solution with a GO suspension. The selectivity of the GO-CS coated QCR was tested when it was exposed to methylamine, dimethylamine, trimethylamine, diethylamine, trimethylamine, acetone, toluene, ethanol, n-hexane, and ethyl acetate. As result of the presence of the high content of hydroxyl groups in the GO-CS nanocomposite, a higher response and selectivity towards the amines was observed in comparison to the other VOCs or when only GO or Cs were employed as coating materials. Moreover, the authors were able to obtain a good lineal relation using this coating, reaching LODs of $1.3 \mathrm{ppm}$ for trimethylamine. In addition, this GO-CS nanocomposite showed good reproducibility, reversibility and long-term stability at room temperature. In another work that involved GO functionalization to provide amido-GO (GO-NH2), the authors also combined these sheets with poly(ethenimine) (PEI) in an amine rich coated QCR to investigate the sensitivity toward acetone detection at an ambient temperature [111]. Zhao and coworkers determined that inclusion of GO-NH2 with PEI increased the sensitivity of acetone vapors 4.2 times compared to PEI. They hypothesized that this effect could not only be a result of an increase in amino groups, but also from the increase in heterogeneity in the morphological properties of the coated QCR.

A more recent study detailed the investigation of two dimensional GO nanosheets employed as QCR sensors [112]. As a result of their high surface area to volume ratio, these nanocoatings were hypothesized to provide good sensitivity to volatile compounds, such as $\mathrm{NO} 2, \mathrm{CO}, \mathrm{SO}_{2}$, and $\mathrm{NH}_{3}$. Two dimensional $\mathrm{GO}$ nanosheets were determined to be the least responsive to $\mathrm{NH}_{3}$, followed by $\mathrm{CO}$, with high recovery times. However, good recovery and response times for other toxic volatile compounds were observed at the time of initial experiments and after four months, indicating the stability of GO nanosheets. In another respect, Langmuir-Blodgett (LB) films of GO were prepared as QCR coatings and adsorption characteristics for several VOCs studied [113]. Volatile gases employed were DCM, benzene, and carbon tetrachloride, and LB films were assembled on the QCR surface. These authors determined that GO-LB films demonstrated sensitivity to each VOC, with the highest frequency response obtained for DCM. As a result of nonlinear processes involved in the adsorption and desorption processes, the authors employed nonlinear autoregressive with an exogenous input neural network (NARX-ANN) to model and obtain diffusion constants that were verified with experimental data.

\subsection{Ionic Liquids (ILs)}

As mentioned previously, sensing capabilities of the QCM measurement systems are based on coatings used to functionalize the surface of the QCR. Coating materials need to be processed and applied in such a manner that optimizes the surface area to allow for maximum adsorption, as well as desorption, of the studied analytes. Although prior coating materials proved be efficient for the detection of certain analytes, interest in ILs as sensing coatings has increased over the years due to their viscoelastic properties, processability, and ease of synthesis and tunability for selective properties [114-118]. As ILs are composed of an organic cation and/or anion, these compounds have tunable properties via simple ion exchange metathesis reactions while maintaining melting points below $100{ }^{\circ} \mathrm{C}$ [119]. Traditional ILs (i.e., imidazolium and phosphonium based ILs) have been used and have been proven effective with developing sensitive arrays, and targeted ILs 
have also been explored for more specific compounds, as discussed below. Figure 7 is a display of the cations and anions commonly employed for ILs synthesis.

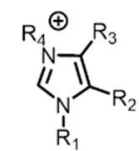

Imidazolium<smiles>Cn1cccc1</smiles>

Pyridinium<smiles>[R][N+]1([R])CCCCC1</smiles>

Piperidinium<smiles>[R9][N+]1([R])CCCC1</smiles>

Pyrrolidinium<smiles>[R][Nb]([R15])[2H]</smiles>

Ammonium<smiles>[R5]P([R5])([R])=O</smiles>

Phosphonium<smiles>FP(F)(F)(F)[P-]</smiles><smiles>O=P(F)(F)P(F)(F)(F)F</smiles>

$\left[\mathrm{BF}_{4}\right]^{-}$

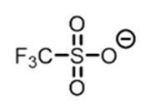

[OTf]<smiles>CN(S(=O)(=O)[O-])S(=O)(=O)C(F)(F)F</smiles>

[NTf2]

$$
\mathrm{F}_{3} \mathrm{C}-\mathrm{C}-\mathrm{C}_{\mathrm{O}} \stackrel{\mathrm{O}}{\mathrm{O}}-\mathrm{N} \stackrel{\Theta}{\Theta} \underset{\mathrm{O}}{\mathrm{O}}-\mathrm{F}_{2}-\mathrm{C}_{3}
$$

$[\mathrm{BETI}]$

Figure 7. Cations and anions commonly employed in ILs synthesis.

\subsubsection{Target-Specific IL Sensors}

As ionic materials are desirable for use as QCM sensory components, many groups have explored the design, synthesis, and capabilities of these valuable materials. Imidazolium have been a specifically targeted cation as materials for reaction-based gas sensing [120]. Tseng and coworkers established a range of chemo-selective imidazolium ILs, employing the [NTf2] as an anion, and using various reactive sites on the imidazolium side chain branches [121]. While their targeted efforts showed good sensitivity toward aldehyde detections, sensitivity to ketones was decreased in one respect. Another targeted IL showed better detection for ketones, but common VOCs were relatively insensitive to these materials (Figure 8).
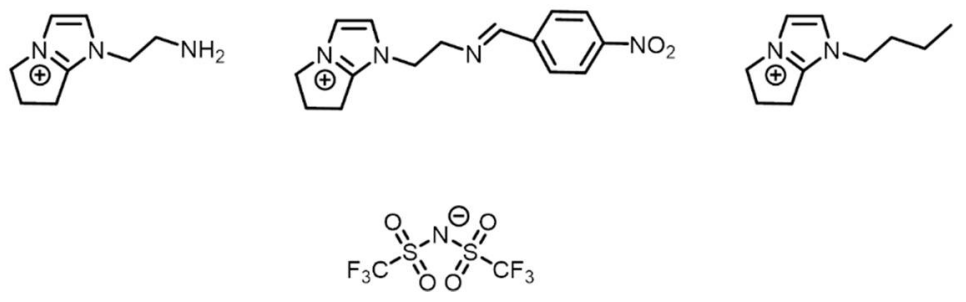

Figure 8. Ionic liquids for targeted VOC detections based on chemical reactions.

In a third IL synthesis, authors targeted amine gas detection and were successful. In most cases, however, studies showed irreversible decreases after sensing procedures. In a similar respect, solvate ILs synthesized from [Li][NTf2] and aromatic substituted tetraglyme were explored by $\mathrm{Chu}$ and coworkers in 2017 [122]. The designed mechanism for these sensors were similar to that from exposure to amine analytes were proposed to undergo covalent functionalization by nucleophilic aromatic substitution. By increasing the electrophilicity of the aromatic ring, the authors were able to successfully produce a sensor for amine gases with little response toward alcohols. This same group produced work involving a combination of imidazolium ILs with azobenzene probes for detecting chemical warfare mimics [123]. By incorporating these complexes, they not only proved useful for QCM coatings, but colorimetric testing as well. These sensing materials are important investigatory achievements, and discrimination of these gases from real-word samples and in the presence of other VOCs would be of prudent interest in future studies.

\subsubsection{IL Sensor Arrays}

The Warner research laboratory has recently explored the utility of synthetically simple ILs as reusable gas-sensing coatings to produce sensor arrays for different classes of VOCs with high accuracies. From this strategy, multi and virtual sensor arrays (MSAs or VSAs) for these systems were reported based on viscoelasticity and film thickness, which 
produced specific response patterns across multiple harmonics [84]. Figure 9 is a display of a schematic representation of QCM-MSAs and QCM-VSAs.

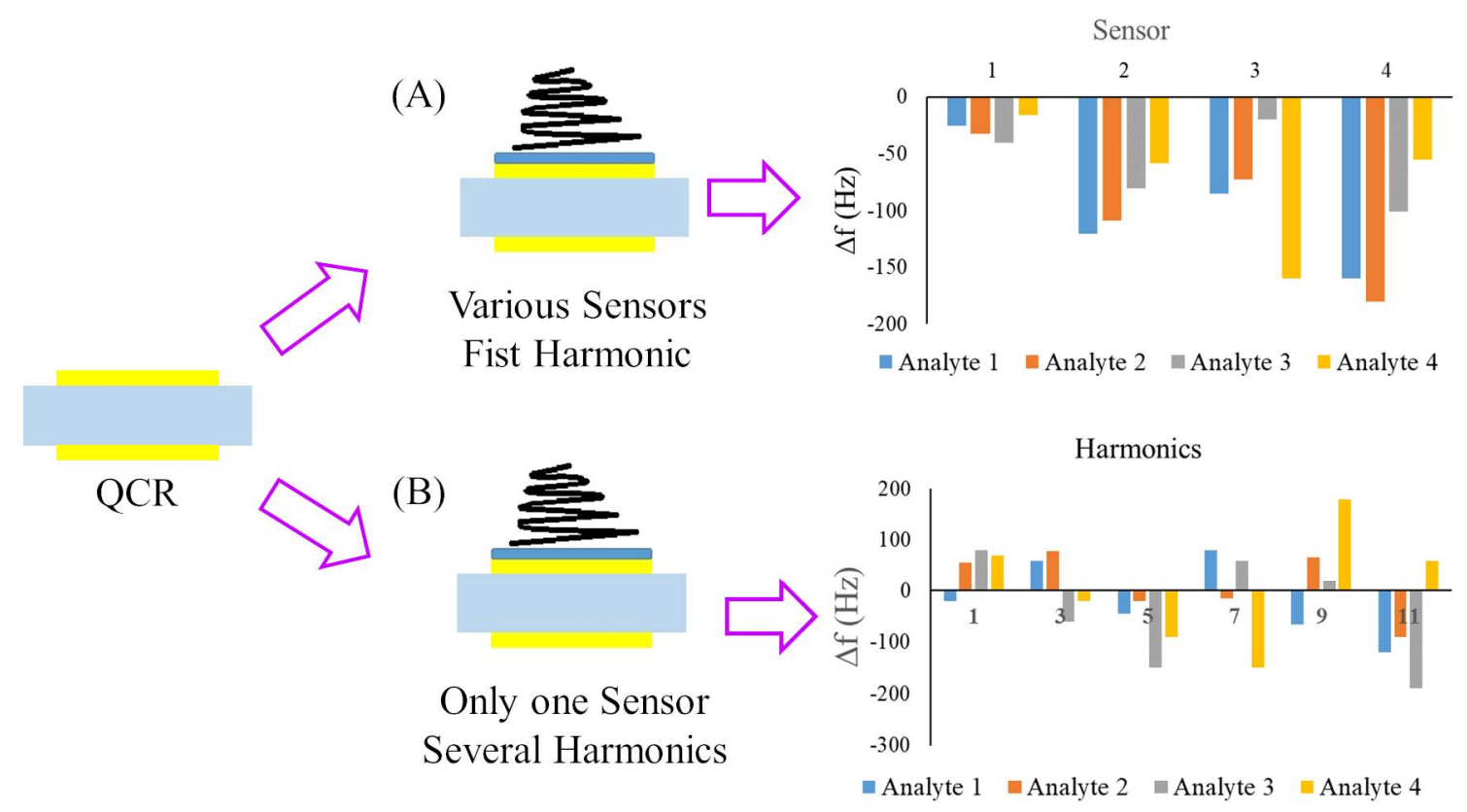

Figure 9. Schematic representation of (A) a QCM-based MSA and (B) a QC-based VSA.

For example, Speller et al. studied two simple ionic liquids [OMIm][Br] and [OMIm][SCN] with two different coating thicknesses obtained through a simple electrospray deposition. In this work, these sensors were exposed to different groups of VOCs like alcohols, hydrocarbons, chlorohydrocarbons and, nitriles. The responses patterns of the change in frequency for different harmonics were collected to build a VSA and to analyze it through PCA and DA, obtaining in this way a high discrimination between the different VOCs. However, better results were obtained when the VSAs were evaluated through quadratic discriminant analysis (QDA). This was proven to reach $100 \%$ accuracy on the discrimination of the studied VOCs.

Similarly, Regmi et al. studied the viscoelastic effects on sensing abilities using four different ILs-[BM2Im][PF6], [HMIm][PF6], [HMPyr][PF6], and [HMIm][TFSI]—in combination with two different polymers (cellulose acetate and polymethylmethacrylate (PMMA)) [124]. As a result of this study, authors were able to discover a relationship between molecular weight and frequency and dissipation changes for structurally related compounds. To further support this theory, Speller et al. produced a study in 2017 that used a VSA to not only identify VOCs, but also to provide information for molecular weight approximation [125]. Employing a low viscosity IL ([HMIm][TFSI]) and PMMA, authors were able to increase the scope of information provided by QCM dissipation techniques with the ability to both provide excellent detection and discrimination between isomers of various alcohols along with molecular weight approximation.

Additionally, Vaughan et al. described anion effects on ionic liquid sensing capabilities by employing trihexyl(tetradecyl)phosphonium as the cation $\left(\left[\mathrm{P}_{66614}\right]^{+}\right)$, and benzenesulfonate $\left([\mathrm{BS}]^{-}\right)$, dodecylbenzenesulfonate $\left([\mathrm{DBS}]^{-}\right)$, and octylbenzenesulfonate ([OBS]-) as anionic components, along with polydimethylsiloxano (PDMS) for improved viscoelastic polymer composites [85]. Upon data analysis, authors found that overall, VSAs based on polymer-IL composites generally were determined to have higher accuracies (100\%) when compared to the MSA at $95.56 \%$ using QDA. After establishing these studies and widening the capabilities of MSAs and VSAs obtained from different IL-sensing materials with multiple harmonics, these strategies were employed for real-world samples and mixture analyses. Imidazolium-based ILs [CXMIm] $[\mathrm{Br}]$ with varying chain lengths $(X=C 8, C 10, C 12$, and $C 16)$ were employed as sensing materials for fuel discrimination (petroleum ether, kerosene, gasoline, and diesel fuel) with excellent accuracies and at various flow rates [126]. 
Notably, these ILs resemble lipid properties, and since lipids are known to be suitable gas sensors, $\left[\mathrm{C}_{9} \mathrm{MIm}\right][\mathrm{SCN}],\left[\mathrm{C}_{9} \mathrm{MIm}\right][\mathrm{Br}],\left[\mathrm{C}_{8} \mathrm{Pyr}\right][\mathrm{Br}]$, and $\left[\mathrm{C}_{11} \mathrm{Pyr}\right][\mathrm{Br}]$ were also used to develop one MSA, four VSAs, and eleven virtual multisensory arrays (V-MSAs) of comparable accuracy for citrus odors [127]. While the MSA and VSAs provided comparable accuracies from $73-98 \%$, by creating V-MSAs with increased data density, sensor array accuracies were improved to $100 \%$ accuracy. As a result of the continued studies for sensor array development, structurally related compounds may be discriminated through simple data analysis.

More recently, Aleixandre and Nakamoto conducted a systematic study of twenty three room-temperature ILs and five stationary phases from gas chromatography were evaluated based on frequency responses and resistance changes upon exposure to four different VOCs [128]. The volatile compounds studied were butyl acetate, hexanol, 2-hexanone, and hexanoic acid, which were comprised of different functional groups with the same number of carbon atoms. Because sensors were studied in groups of four, Wilks-lambda analysis was employed to evaluate the relative significant differences among sensor responses within each group. When both frequency and resistance responses were considered, the four sensors with the lowest Wilks-lambda included two GC stationary phases, Tricresyl phosphate and Apiezon-L, with ILs [Py $\left.{ }_{41}\right][\mathrm{NTf} 2]$ and $\left[\mathrm{C}_{6} \mathrm{MIm}\right]\left[\mathrm{PF}_{6}\right]$. These investigators employed LDA for fabricated sensor arrays and obtained a substantial separation of all VOCs. Validation experiments were performed and achieved with banana and pineapple flavors. Overall, these researchers established a method in which to systematically study and construct sensor arrays from ILs for target analytes [128].

\subsection{Macrocyclic Sensors}

While different coatings like polymers, ILs, and more possess many desirable attributes to promote sensitive and rapid detection of VOCs, macrocyclic compounds such as cyclodextrins (CDs) [129-131], calixarenes [132-135], and phthalocyanines have proven useful as sensitive coating agents. Several groups have studied their VOC-sensing properties in various sensor arrays as their structures promote host-guest interactions with various compounds. In some cases, these materials have been incorporated both as doping materials and as the sole coating materials for sensing. As others have provided comprehensive details on CDs as vapor sensing coatings [131,136], this section focuses on recent developments on calixarenes and phthalocyanines for VOC detection with QCM systems.

\subsubsection{Calixarenes}

Calixarenes are macrocyclic structures bearing aromatic rings with host-guest characteristic properties. Similar to CDs, they contain a cage-like structure that can be tuned through common synthetic organic strategies. Calix[4]arene is the most widely studied form of this macrocycle, and R1, R2, R3 and/or R4 are often modified to improve selectivity (Figure 10). For example, Temel and Tabacki reported in 2016 the use of various substituent groups on these positions to examine sensing properties to a variety of different VOCs. They found, however, that the strongest response was to methylene chloride with the best detection limit achieved at $54.1 \mathrm{ppm}$ from aqueous systems [128].

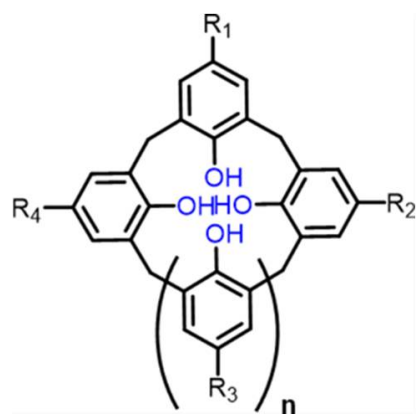

Figure 10. General structure of Calix(n)arenes, where n could be equal or higher than 4 . 
In another work, Temel and coworkers used an R2-bromopropyl functionalized calix[4]arene for sensor development, and determined that this compound was most sensitive to toluene vapors in aqueous media [129]. On the other hand, modification of this same position with a triazine structure was reported by Halay and coworkers in 2019. This modification provided the greatest sensitivities to chlorinated hydrocarbons dichloromethane $>$ chloroform $>$ carbon tetrachloride [131]. Finally, an amino morpholine modified calix[4]arene was also investigated for multiple VOC sensing, and was determined to have a high response to formaldehyde vapor. The sensitivity of this system was determined to be $0.67 \mathrm{ppm}$. Selectivity of this sensor for $1.85 \mathrm{ppm}$ formaldehyde was established under relative humidities ranging from $33 \%$ to $97 \%$, as well as in the presence of other potentially interfering VOCs that were maintained at $30 \mathrm{ppm}$ with $97 \%$ relative humidity. While all sensors in these investigations were developed and obtained specific analyte responses, sensor arrays to discriminate between gases were not established in these studies, which could be attributed to low intermolecular forces and low sensitivity as a result of relatively small inner cavities.

In this respect, Acikbas and coworkers investigated the use of pillar[5]arenes (P5-P4) for chlorohydrocarbons VOC detection and discrimination [133]. By incorporating a larger central cavity along with strategic functionalization, these authors hypothesized that monolayers of this sensing material would provide more substantial host-guest interactions. In this work, P5-P4s were similar to the general calix[n]arene structure depicted in Figure 9, where $\mathrm{n}$ equals 2 . These investigators functionalized central hydroxyl groups, along with the appending $R$ side chains, that were substituted for ether-linked aminopyridine terminal groups. Langmuir-blodgett films were produced, characterized, and coated onto QCRs to be employed in chlorohydrocarbon detection and discrimination. Dichloromethane (DCM), chloroform, and carbon tetrachloride were employed as VOCs for QCM measurements. Sensitivity values and limits of detection for the VOCs were determined to be between 7.61-2.16 Hz ppm and 0.39-1.38, respectively. Two deep learning algorithms were used to train prediction models for diffusion constant determination with 100 measurements: (1) nonlinear autoregressive neural networks (NARNET) and (2) long short-term memory (LSTM). By employing 20 sampling points for verification, these investigators determined that LSTM predicted values for chloroform and carbon tetrachloride vapors when compared to NARNET. In contrast, NARNET was determined to be a better prediction model for DCM vapors as a result of highly nonlinear measurements influenced by diffusion characteristics. By employing a hybrid model, investigators verified that both models were suitable to provide predictive properties with a 0.98 correlation coefficient [133].

\subsubsection{Phthalocyanines Sensors}

Phthalocyanines are a class of macrocyclic polyaromatic carbons, similar to calixarenes, that often contain a metal center, such as nickel $\left(\mathrm{Ni}^{2+}\right)$, zinc $\left(\mathrm{Zn}^{2+}\right)$, copper $\left(\mathrm{Cu}^{2+}\right)$, or more than 60 other metal atoms [134]. A general structure of the phthalocyanine ring is represented in Figure 11. They have been extensively studied in various applications such as their 18p electron core and peripheral carbon units may be covalently functionalized to lend unique chemical, photophysical, and electronic properties. As a result of their electrical responsiveness in response to various stimuli, many iterations of phthalocyanines have been employed as QCR coatings for VOC detection. For example, Harbeck and coworkers studied the substituent effects about the periphery of the phthalocyanine macrocycle, as well as examining central metallic atom effects on organic compound detection in both liquid and gaseous states [134]. The authors found that in aqueous states, sensors were able to detect desired analytes in the parts-per-million range, and sensors with 2,2,3,3-tetrafluoropropyloxy units displayed a greatest sensitivity to VOCs, with $\mathrm{Cu}^{2+}$ as the central atom displaying the greatest sensitivity as determined by partition coefficient determination. Overall, investigators confirmed the general reversibility and reliability of phthalocyanines as sensors for VOC detection. 


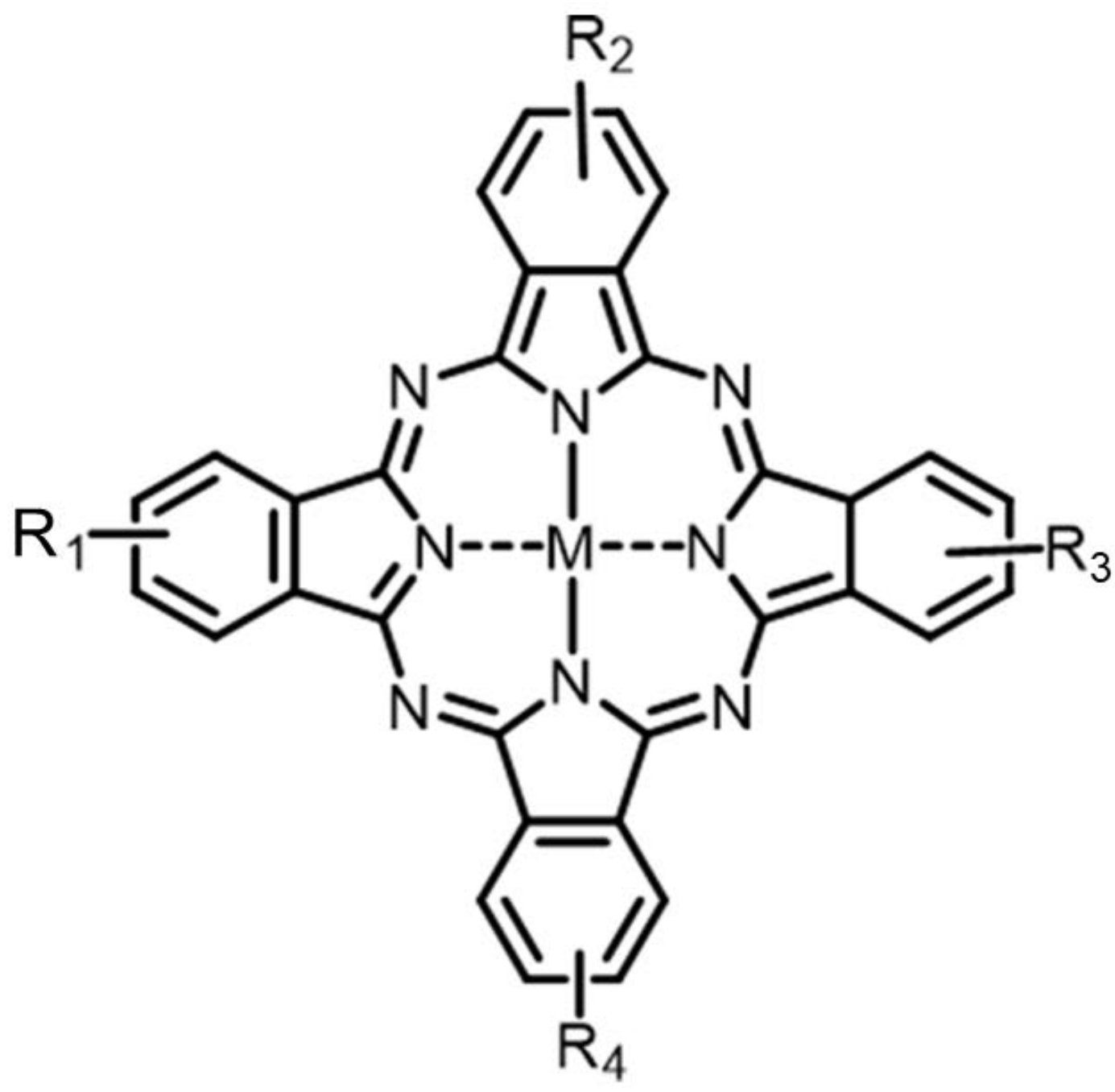

Figure 11. General structure of Phthalocyanines.

Toxic VOCs under specific regulation and monitoring, such as benzene, toluene, and xylenes (BTX), have also been used as samples for phthalocyanine sensor development $[135,136]$. In one study conducted in 2015, authors explore and evaluate various side chains along copper(II) phthalocyanines for investigations into sensitivity for reliable toluene detection [136]. Investigators determined that tert-butyl ligands improved the overall rate of the adsorption and desorption processes as the tert-butyl ligands provide dispersive forces upon removal of toluene vapor. This tetra-substituted tert-butyl phthalocyanine sensor was determined to have excellent repeatability and sensitivity to toluene exposure with a response and recovery times for thermodynamic equilibrium of three minutes each. Similarly, Kumar et al. investigated unsubstituted phthalocyanines with various (iron, cobalt, zinc, and copper) metallic cores as well as respective tetra tert-butyl and hexadecafluoro-phthalocyanines to assess the sensitivity and related trends of each compound to toluene detection in aqueous environments [135]. The authors confirmed that no significant changes in responses were determined with the change of metallic atom, but substitutions along the periphery remained a substantial influence. $\mathrm{Cu}^{+}$cores maintained the fastest response and recovery times, and tetra tert-butyl groups showed the greatest sensitivity for toluene vapor over hexadecafluoro-phthalocyanines, presumably due to the electronic effects involved in fluorine substitution that do not promote toluene adsorption. As these studies prove to have a useful input for determining the substituent effects on vapor detection, arrays for distinguishing between BTX remain to be explored. 


\subsubsection{Phthalocyanines Sensors}

As exploring chain lengths as well as anion effects has proven beneficial for exploring QCM-D capabilities with simple ILs, this strategy has also been applied to easily tune phthalocyanine peripheral sites to improve VOC detection and sensor array development. In this respect, several investigations have been reported on the use of groups of uniform materials based on organic salts (GUMBOS) [113], a class of solid phase ionic compounds with melting points between 25 and $250^{\circ} \mathrm{C}$, as sensing materials. For this reason, Regmi et al. first reported combining the properties of these macrocycles with [P66614] cations in 2015 [137].

Anionic copper(II)phthalocyanine, along with copper(II) porphyrin GUMBOS, were formed using a simple cation exchange metathesis reaction to obtain [P66614]4[CuTCPP] and [P66614]4[CuPS4] sensing materials [137]. These authors found that these macrocylic GUMBOS were suitable materials for excellent VOC detection and discrimination. To further explore the tunability of these phthalocyanine GUMBOS and explore VOC sensitivity, Vaughan et al. synthesized a variety of copper(II) phthalocyanines ([CuPS4]) GUMBOS with various cations ([DDMA], [P4444], [N4444], and [P4448]) [86]. With ion exchange, authors found that each novel sensor produced desired analyte responses to discriminate into four different classes alcohols, chlorohydrocarbons, aromatic hydrocarbons, and hydrocarbons. High accuracies (98.6\%) were obtained by QDA and employing original data sets in lieu of principal components, which are traditionally used for accuracy analysis.

\section{Electronic Devices}

As described in previous sections, a great amount of effort has been targeted toward sensor and sensor array development to detect and distinguish VOCs based on QCR coatings. Another area of interest for this gravimetric system in recent years has been in the development of the capabilities of electronic devices. In this section, we also briefly review the types of QCM instruments currently in use, as well as their advantages and limitations.

\subsection{General QCR Signal Output through QCM Devices}

As a QCR interacts with target molecules, the resonator gains a certain amount of mass, causing a piezoelectric resonance change, which then needs to be measured by a QCM instrument to quantify the mass or resonance change. Electronic instruments employed for QCM measurements usually have three different types of operation principles: impedance, oscillation, and dissipation. An oscillation-based system is suitable for most gas phase applications, while systems based on impedance and dissipation measurements are typically preferred for high damping applications under the liquid phase. Impedance responses from the QCR can be obtained by implementing a sweeping frequency. In this manner, an impedance spectrum generated can then be used to determine the resonance frequency and power dissipation of the QCR. In an oscillation-based measurement, the QCR is connected to an oscillation circuit that is designed as a positive feedback system to compensate for energy loss of the resonator, and thus enables continuous oscillation of the resonator. A resonance frequency shift of the QCR is then measured by a digital frequency counter circuit. Another type of measurement uses a ring-down technique, which is known as QCM, with dissipation monitoring (QCM-D). In this circuit, QCM-D measurements analyze the resonance frequency and power dissipation of the QCR after a short period of excitation to monitor molecular interactions at the surface of the resonator in real-time. In general, an oscillation-based system is suitable for most gas-phase applications, while systems based on impedance and dissipation measurements are typically preferred for high damping applications under the liquid phase. Figure 12 illustrates brief concepts of the three major measurement types for QCM. 


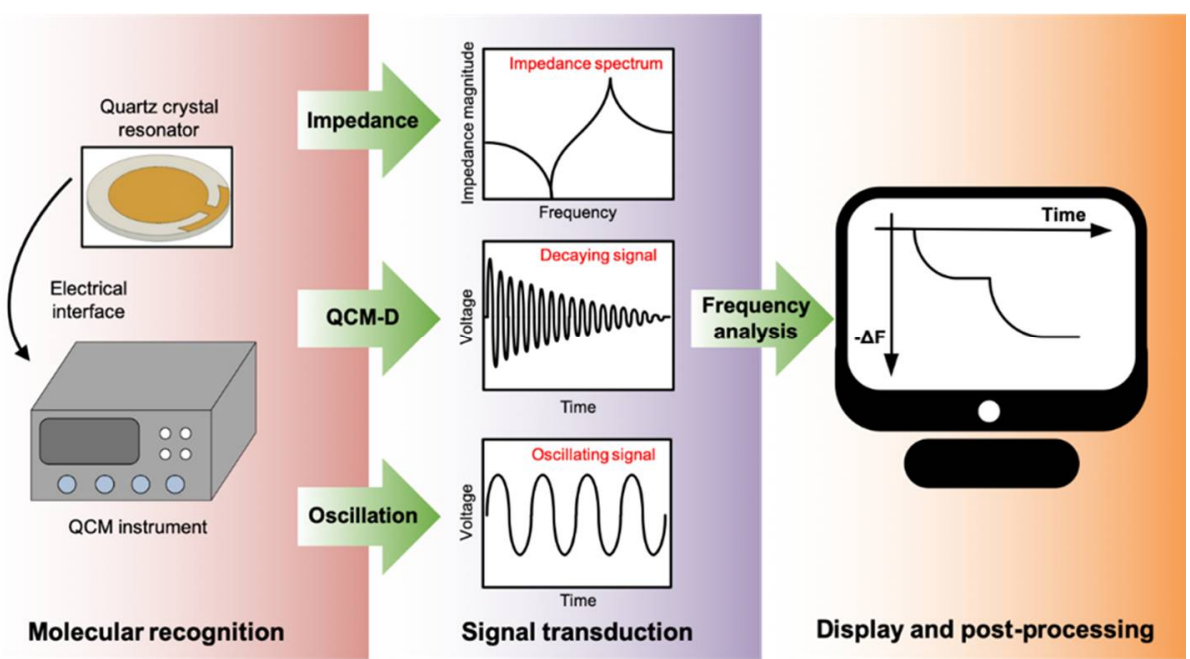

Figure 12. Brief concepts illustrating three different types of quartz crystal microbalance sensing instruments including impedance analysis, quartz crystal microbalance with dissipation monitoring (QCM-D), and oscillation-based measurements.

\subsection{Impedance-Based Measurement System}

The mechanical resonance of a QCR is traditionally analyzed by investigating the piezoelectric response of QCR with an equivalent electrical circuit model having capacitance, inductance, and resistance, or impedance all together [137]. In the equivalent electrical model, capacitance and inductance reflect mechanical elasticity and inertia of the piezoelectric resonator, which ultimately determine the resonance frequency. Resistance represents energy loss by the QCR. Molecular reactions on the surface of a QCR causes a change in the equivalent electrical model, resulting in a change in impedance that can be measured by an electronic instrument. In general, an impedance plot is obtained by a sweeping frequency to the QCR to detect impedance changes of the resonator in realtime. An impedance measurement offers high accuracy compared to other measurement techniques but requires sophisticated and costly instrumentation [138].

Several electronic systems have been suggested to replace a powerful, yet expensive, impedance measurement system like a network analyzer. Reported systems operate in a similar principle of the traditional impedance measurement system, but they target a reduction in measurement times toward real-time monitoring [139], improvements in parameter extraction efficiency from the equivalent electrical model $[140,141]$, and miniaturization of the system for portable applications [142,143]. A recent study reported an impedance measurement system with a measurement time of $1-5 \mathrm{~ms}$ at a given frequency point [139]. Voltage or impedance division methods have been proposed to measure the magnitude of the resonator output signal instead of obtaining the impedance spectrum. Thus, the equivalent electrical model components could be extracted using a transfer function of the system $[140,141]$. Compact interface circuits have also been proposed to miniaturize measurement instruments for portable applications $[143,144]$, but a true portable QCM instrument has not yet been demonstrated.

\subsection{QCM with Dissipation Monitoring (QCM-D)}

The ring-down technique is usually called a QCM with a dissipation monitoring (QCM-D) method after the Q-Sense Analyzer (Biolin Scientific, Gothenburg, Sweden) commercialized in 1996 [145]. In this technique, an oscillation signal near the resonance frequency is applied to a QCR in a short period time. When the applied oscillation signal is turned off, a signal from the QCR starts to exponentially decay due to energy loss, and this decaying pattern is monitored in real-time to obtain the resonance frequency and dissipation factor (D) [146]. The actual resonance frequency of a QCR is determined by the dissipation factor and oscillating frequency of the decaying signal. QCM-D allowed contactless sensor technology in 
which impulse excitation and decaying signals from the resonator are wirelessly transferred via electromagnetic coupling between two coils connected to the main circuit system and the QCR [147,148]. A wireless QCM-D technique has recently been implemented in the discrimination of VOCs with a single QCR coated with polyvinylpyrrolidone (PVP) [148]. This QCM-D technique is advantageous in viscoelastic environments, but the instrument is costly due to the requirement of high-quality system components.

\subsection{Oscillator-Based Measurement System}

Oscillation changes caused by molecular absorption on a QCR can directly be measured using proper electronic instruments. Oscillation circuits are usually designed as a positive feedback system providing enough power to maintain oscillation. In QCM, the piezoelectric resonator plays a role as an electrical filter with other electrical components [149]. Ideally, an oscillation circuit or an oscillator produces an alternating signal whose frequency is the resonance frequency of the QCR. However, an oscillation frequency is also affected by the amount of power dissipation of the QCR [150]. The accuracy of the oscillator-based measurement can be lower in a high damping medium like water due to a significant increase in power dissipation.

A frequency counter is the simplest and most common way to measure the change in frequency of oscillation signal. A frequency counter circuit usually consists of digital timers and counters and provides high precision at simple design [151]. The simplest frequency counter tallies the number of input pulses over a pre-defined measurement time. However, in this type of counter, measurement time should be increased in order to obtain a better frequency resolution. A reciprocal counter has also been introduced to enhance the frequency resolution and obtain faster measurement times [152,153], which provides an accurate time measurement using a high-frequency reference signal for a certain number of oscillation signal pulses [152]. As the name suggests, the frequency is calculated based on the measured time in a reciprocal counter.

An interesting measurement system has been proposed for very fast QCM applications like electrochemical QCM (EQCM) [154,155]. The proposed system used a phase-locked loop circuit as a frequency-to-voltage converter. This class of system showed a measurement time of 1 millisecond, which is difficult to achieve by other measurement systems.

Recent trends in QCM measurement electronics focus on developing low-cost, portable, and multi-sensor QCM systems. A commercial data acquisition system offered by OpenQCM (Novaetech, Italy) has been widely used as a low-cost and easily operated QCM measurement system $[156,157]$. However, since the OpenQCM system is limited to singlechannel operation, it cannot directly be used for QCM-based sensor arrays. Recently, a four-channel data acquisition system has been proposed for an e-nose application. Four individual counters embedded in a microcontroller calculate the frequencies of the four input signals.

Overall, the impedance measurement provides high accuracy and would be suitable for applications not requiring fast measurements due to its relatively slow measurement speed. When a rapid measurement is desired, QCM-D or oscillator-based measurements would be a more practical selection. QCM-D has a strong advantage in power dissipation monitoring with a high accuracy, especially for applications in a high damping medium. For simple resonance frequency measurements in a low damping medium, oscillator-based measurements can provide a cost-effective option.

\section{Conclusions}

Due to the detrimental effects that VOCs produce in human health, animals, plants, and the general environment, detection and discrimination of these organic compounds is of crucial importance. The working principle of the QCM allows the scientific community to explore and employ several types of materials to coat the QCR. Different types of coating materials have been reported in the past two decades, where these could be chosen to be more selective and sensitive towards a specific type of VOC. New and different 
combinations of coating materials could be used to develop a sensor array in order to improve the selectivity and sensitivity for VOC detection.

Moreover, it is also important to have precise and rapid methods for the detection of different VOCs. This device has been proven to be fast, sensitive, and cost effective for the study of a broad variety of VOCs. For this reason, the use of QCM devices for VOC detection, as well as electronic system development, has increased in the past two decades.

Author Contributions: Conceptualization—original draft preparation and editing, R.L.P. and C.E.A.; writing, J.-Y.P. and J.-W.C.; review and editing, I.M.W.; funding acquisition, I.M.W. All authors have read and agreed to the published version of the manuscript.

Funding: The authors gratefully acknowledge financial support through NASA cooperative agreement NNX 16AQ93A under contract number NASA/LEQSF (2016-19)-Phase 3-10, and the National Science Foundation under Grant Nos. CHE-1905105 and HRD-1736136. Any opinions, findings, and conclusions or recommendations expressed in this material are those of the author(s) and do not necessarily reflect the views of the National Science Foundation.

Institutional Review Board Statement: Not applicable.

Informed Consent Statement: Not applicable.

Data Availability Statement: Not applicable.

Conflicts of Interest: The authors declare no conflict of interest.

\section{References}

1. EPA. What Is the Definition of VOC? Available online: https://www.epa.gov/air-emissions-inventories/what-definition-voc (accessed on 1 May 2021).

2. EPA. Technical Overview of Volatile Organic Compounds. Available online: https://www.epa.gov/indoor-air-quality-iaq/ technical-overview-volatile-organic-compounds\#definition (accessed on 1 May 2021).

3. Owen, S.M.; Clark, S.; Pompe, M.; Semple, K.T. Biogenic volatile organic compounds as potential carbon sources for microbial communities in soil from the rhizosphere of Populus tremula. FEMS Microbiol. Lett. 2007, 268, 34-39. [CrossRef]

4. Maleknia, S.D.; Bell, T.L.; Adams, M.A. Eucalypt smoke and wildfires: Temperature dependent emissions of biogenic volatile organic compounds. Int. J. Mass Spectrom. 2009, 279, 126-133. [CrossRef]

5. Aaltonen, H.; Aalto, J.; Kolari, P.; Pihlatie, M.; Pumpanen, J.; Kulmala, M.; Nikinmaa, E.; Vesala, T.; Bäck, J. Continuous VOC flux measurements on boreal forest floor. Plant Soil 2013, 369, 241-256. [CrossRef]

6. Kesselmeier, J.; Kuhn, U.; Wolf, A.; Andreae, M.O.; Ciccioli, P.; Brancaleoni, E.; Frattoni, M.; Guenther, A.; Greenberg, J.; De Castro Vasconcellos, P.; et al. Atmospheric volatile organic compounds (VOC) at a remote tropical forest site in central Amazonia. Atmos. Environ. 2000, 34, 4063-4072. [CrossRef]

7. Qin, Y.; Walk, T.; Gary, R.; Yao, X.; Elles, S. C2-C10 nonmethane hydrocarbons measured in Dallas, USA-Seasonal trends and diurnal characteristics. Atmos. Environ. 2007, 41, 6018-6032. [CrossRef]

8. Hou, X.; Strickland, M.J.; Liao, K.-J. Contributions of regional air pollutant emissions to ozone and fine particulate matter-related mortalities in eastern U.S. urban areas. Environ. Res. 2015, 137, 475-484. [CrossRef] [PubMed]

9. Wei, W.; Lv, Z.; Yang, G.; Cheng, S.; Li, Y.; Wang, L. VOCs emission rate estimate for complicated industrial area source using an inverse-dispersion calculation method: A case study on a petroleum refinery in Northern China. Environ. Pollut. 2016, 218, 681-688. [CrossRef]

10. Hardoyono, F.; Windhani, K.; Sambodo, H.; Pudjianto, H. Identification of Bioactive Compounds in Ginger Based on Molecularly Imprinted Polymer Quartz Crystal Microbalance Gas Sensor. IOP Conf. Ser. Mater. Sci. Eng. 2019, 546, 032012. [CrossRef]

11. Majchrzak, T.; Wojnowski, W.; Dymerski, T.; Gebicki, J.; Namieśnik, J. Electronic noses in classification and quality control of edible oils: A review. Food Chem. 2018, 246, 192-201. [CrossRef]

12. Wen, T.; Sang, M.; Wang, M.; Han, L.; Gong, Z.; Tang, X.; Long, X.; Xiong, H.; Peng, H. Rapid detection of d-limonene emanating from citrus infestation by Bactrocera dorsalis (Hendel) using a developed gas-sensing system based on QCM sensors coated with ethyl cellulose. Sens. Actuators B Chem. 2021, 328, 129048. [CrossRef]

13. Bwambok, D.K.; Siraj, N.; Macchi, S.; Larm, N.E.; Baker, G.A.; Pérez, R.L.; Ayala, C.E.; Walgama, C.; Pollard, D.; Rodriguez, J.D. QCM Sensor Arrays, Electroanalytical Techniques and NIR Spectroscopy Coupled to Multivariate Analysis for Quality Assessment of Food Products, Raw Materials, Ingredients and Foodborne Pathogen Detection: Challenges and Breakthroughs. Sensors 2020, 20, 6982. [CrossRef] [PubMed]

14. Amann, A.; Costello, B.d.L.; Miekisch, W.; Schubert, J.; Buszewski, B.; Pleil, J.; Ratcliffe, N.; Risby, T. The human volatilome: Volatile organic compounds (VOCs) in exhaled breath, skin emanations, urine, feces and saliva. J. Breath Res. $2014,8,034001$. [CrossRef] 
15. Güntner, A.T.; Abegg, S.; Königstein, K.; Gerber, P.A.; Schmidt-Trucksäss, A.; Pratsinis, S.E. Breath Sensors for Health Monitoring. ACS Sens. 2019, 4, 268-280. [CrossRef] [PubMed]

16. Sánchez, C.; Santos, J.P.; Lozano, J. Use of electronic noses for diagnosis of digestive and respiratory diseases through the breath. Biosensors 2019, 9, 35. [CrossRef] [PubMed]

17. Sola Martínez, R.A.; Pastor Hernández, J.M.; Yanes Torrado, Ó.; Cánovas Díaz, M.; de Diego Puente, T.; Vinaixa Crevillent, M. Exhaled volatile organic compounds analysis in clinical pediatrics: A systematic review. Pediatri. Res. 2020. [CrossRef] [PubMed]

18. Janfaza, S.; Nojavani, M.B.; Nikkhah, M.; Alizadeh, T.; Esfandiar, A.; Ganjali, M.R. A selective chemiresistive sensor for the cancer-related volatile organic compound hexanal by using molecularly imprinted polymers and multiwalled carbon nanotubes. Microchim. Acta 2019, 186, 137. [CrossRef] [PubMed]

19. Zhao, S.; Lei, J.; Huo, D.; Hou, C.; Luo, X.; Wu, H.; Fa, H.; Yang, M. A colorimetric detector for lung cancer related volatile organic compounds based on cross-response mechanism. Sens. Actuators B Chem. 2018, 256, 543-552. [CrossRef]

20. Janssens, E.; van Meerbeeck, J.P.; Lamote, K. Volatile organic compounds in human matrices as lung cancer biomarkers: A systematic review. Crit. Rev. Oncol. Hematol. 2020, 153, 103037. [CrossRef]

21. Wang, L.; Wu, Y.; Li, G.; Xu, H.; Gao, J.; Zhang, Q. Superhydrophobic n-octadecylsiloxane (PODS)-functionalized PDA-PEI film as efficient water-resistant sensor for ppb-level hexanal detection. Chem. Eng. J. 2020, 399, 125755. [CrossRef]

22. Behera, B.; Joshi, R.; Vishnu, G.A.; Bhalerao, S.; Pandya, H.J. Electronic nose: A non-invasive technology for breath analysis of diabetes and lung cancer patients. J. Breath Res. 2019, 13, 024001. [CrossRef]

23. Saidi, T.; Zaim, O.; Moufid, M.; El Bari, N.; Ionescu, R.; Bouchikhi, B. Exhaled breath analysis using electronic nose and gas chromatography-mass spectrometry for non-invasive diagnosis of chronic kidney disease, diabetes mellitus and healthy subjects. Sens. Actuators B Chem. 2018, 257, 178-188. [CrossRef]

24. Dragonieri, S.; Scioscia, G.; Quaranta, V.N.; Carratu, P.; Venuti, M.P.; Falcone, M.; Carpagnano, G.E.; Barbaro, M.P.F.; Resta, O.; Lacedonia, D. Exhaled volatile organic compounds analysis by e-nose can detect idiopathic pulmonary fibrosis. J. Breath Res. 2020, 14, 047101. [CrossRef] [PubMed]

25. Sarno, R.; Sabilla, S.I.; Wijaya, D.R. Electronic Nose for Detecting Multilevel Diabetes Using Optimized Deep Neural Network. Eng. Lett. 2020, 28, 31-42.

26. Van Keulen, K.E.; Jansen, M.E.; Schrauwen, R.W.; Kolkman, J.J.; Siersema, P.D. Volatile organic compounds in breath can serve as a non-invasive diagnostic biomarker for the detection of advanced adenomas and colorectal cancer. Aliment. Pharmacol. Ther. 2020, 51, 334-346. [CrossRef]

27. Ramírez, N.; Cuadras, A.; Rovira, E.; Borrull, F.; Marcé, R.M. Comparative study of solvent extraction and thermal desorption methods for determining a wide range of volatile organic compounds in ambient air. Talanta 2010, 82, 719-727. [CrossRef]

28. Samide, M.J.; Smith, G.D. Analysis and quantitation of volatile organic compounds emitted from plastics used in museum construction by evolved gas analysis-gas chromatography-mass spectrometry. J. Chromatogr. A 2015, 1426, 201-208. [CrossRef]

29. Nikolaou, A.D.; Golfinopoulos, S.K.; Kostopoulou, M.N.; Kolokythas, G.A.; Lekkas, T.D. Determination of volatile organic compounds in surface waters and treated wastewater in Greece. Water Res. 2002, 36, 2883-2890. [CrossRef]

30. Faiola, C.L.; Erickson, M.H.; Fricaud, V.L.; Jobson, B.T.; VanReken, T.M. Quantification of biogenic volatile organic compounds with a flame ionization detector using the effective carbon number concept. Atmos. Meas. Tech. 2012, 5, 1911-1923. [CrossRef]

31. Jia, M.; Koziel, J.; Pawliszyn, J. Fast field sampling/sample preparation and quantification of volatile organic compounds in indoor air by solid-phase microextraction and portable gas chromatography. Field Anal. Chem. Technol. 2000, 4, 73-84. [CrossRef]

32. Liu, H.-W.; Liu, Y.-T.; Wu, B.-Z.; Nian, H.-C.; Chen, H.-J.; Chiu, K.-H.; Lo, J.-G. Process sampling module coupled with purge and trap-GC-FID for in situ auto-monitoring of volatile organic compounds in wastewater. Talanta 2009, 80, 903-908. [CrossRef] [PubMed]

33. Park, C.; Schade, G.W.; Boedeker, I. Flux measurements of volatile organic compounds by the relaxed eddy accumulation method combined with a GC-FID system in urban Houston, Texas. Atmos. Environ. 2010, 44, 2605-2614. [CrossRef]

34. Michalczuk, B.; Moravský, L.; Hrdá, J.; Matejčík, Š. Atmospheric Pressure Chemical Ionisation study of selected Volatile Organic Compounds (VOCs) by Ion Mobility Spectrometry coupled with orthogonal acceleration Time of Flight Mass Spectrometry. Int. J. Mass Spectrom. 2020, 449, 116275. [CrossRef]

35. Moura, P.C.; Vassilenko, V.; Fernandes, J.M.; Santos, P.H. Indoor and Outdoor Air Profiling with GC-IMS. In Doctoral Conference on Computing, Electrical and Industrial Systems; Springer: Cham, Switzerland, 2020; pp. 437-444.

36. Xue, B.; Sun, L.; Huang, Z.; Gao, W.; Fan, R.; Cheng, P.; Ding, L.; Ma, L.; Zhou, Z. A hand-portable digital linear ion trap mass spectrometer. Analyst 2016, 141, 5535-5542. [CrossRef]

37. La Nasa, J.; Lomonaco, T.; Manco, E.; Ceccarini, A.; Fuoco, R.; Corti, A.; Modugno, F.; Castelvetro, V.; Degano, I. Plastic breeze: Volatile organic compounds (VOCs) emitted by degrading macro- and microplastics analyzed by selected ion flow-tube mass spectrometry. Chemosphere 2020, 128612. [CrossRef]

38. Lin, W.; Li, Z. Detection and quantification of trace organic contaminants in water using the FT-IR-attenuated total reflectance technique. Anal. Chem. 2010, 82, 505-515. [CrossRef] [PubMed]

39. Pogodina, O.A.; Pustogov, V.V.; De Melas, F.; Haberhauer-Troyer, C.; Rosenberg, E.; Puxbaum, H.; Inberg, A.; Croitoru, N.; Mizaikoff, B. Combination of sorption tube sampling and thermal desorption with hollow waveguide FT-IR spectroscopy for atmospheric trace gas analysis: Determination of atmospheric ethene at the lower ppb level. Anal. Chem. 2004, 76, 464-468. [CrossRef] [PubMed] 
40. Marks, A. The Human Nose Knows More Than We Think. 2017. Available online: https://www.scientificamerican.com/article/ the-human-nose-knows-more-than-we-think/ (accessed on 1 May 2021).

41. Williams, S.C.P. Human nose can detect a trillion smells. Science 2014, 372, 3-20.

42. Gardner, J.W.; Bartlett, P.N. Electronic Noses: Principles and Applications; Oxford University Press: Oxford, UK, 1999.

43. Persaud, K.; Dodd, G. Analysis of discrimination mechanisms in the mammalian olfactory system using a model nose. Nature 1982, 299, 352-355. [CrossRef] [PubMed]

44. Matatagui, D.; Kolokoltsev, O.V.; Qureshi, N.; Mejía-Uriarte, E.V.; Ordoñez-Romero, C.L.; Vázquez-Olmos, A.; Saniger, J.M. Magnonic sensor array based on magnetic nanoparticles to detect, discriminate and classify toxic gases. Sens. Actuators B Chem. 2017, 240, 497-502. [CrossRef]

45. Song, Z.; Tang, Q.; Tong, Y.; Liu, Y. High-Response Identifiable Gas Sensor Based on a Gas-Dielectric ZnPc Nanobelt FET. IEEE Electron Device Lett. 2017, 38, 1586-1589. [CrossRef]

46. Moon, H.G.; Han, S.D.; Kang, M.-G.; Jung, W.-S.; Jang, H.W.; Yoo, K.S.; Park, H.-H.; Kang, C.Y. Chemiresistive sensor array based on semiconducting metal oxides for environmental monitoring. J. Sens. Sci. Technol. 2014, 23, 15-18. [CrossRef]

47. Righettoni, M.; Amann, A.; Pratsinis, S.E. Breath analysis by nanostructured metal oxides as chemo-resistive gas sensors. Mater. Today 2015, 18, 163-171. [CrossRef]

48. Horsfall, L.A.; Pugh, D.C.; Blackman, C.S.; Parkin, I.P. An array of WO 3 and CTO heterojunction semiconducting metal oxide gas sensors used as a tool for explosive detection. J. Mater. Chem. A 2017, 5, 2172-2179. [CrossRef]

49. Mascini, M.; Gaggiotti, S.; Della Pelle, F.; Di Natale, C.; Qakala, S.; Iwuoha, E.; Pittia, P.; Compagnone, D. Peptide modified ZnO nanoparticles as gas sensors array for volatile organic compounds (VOCs). Front. Chem. 2018, 6, 105. [CrossRef]

50. Gao, F.; Xuan, W.; Bermak, A.; Boussaid, F.; Tsui, C.-Y.; Luo, J. Dual transduction on a single sensor for gas identification. Sens. Actuators B Chem. 2019, 278, 21-27. [CrossRef]

51. Harun, F.K.C.; Jumadi, A.M.; Mahmood, N.H. Carbon black polymer composite gas sensor for electronic nose. Methods 2011, 6.

52. Esteves, C.H.A.; Iglesias, B.A.; Li, R.W.C.; Ogawa, T.; Araki, K.; Gruber, J. New composite porphyrin-conductive polymer gas sensors for application in electronic noses. Sens. Actuators B Chem. 2014, 193, 136-141. [CrossRef]

53. Benvenho, A.R.; Li, R.W.; Gruber, J. Polymeric electronic gas sensor for determining alcohol content in automotive fuels. Sens. Actuators B Chem. 2009, 136, 173-176. [CrossRef]

54. Chang, J.B.; Liu, V.; Subramanian, V.; Sivula, K.; Luscombe, C.; Murphy, A.; Liu, J.; Fréchet, J.M. Printable polythiophene gas sensor array for low-cost electronic noses. J. Appl. Phys. 2006, 100, 014506. [CrossRef]

55. Gebicki, J. Application of electrochemical sensors and sensor matrixes for measurement of odorous chemical compounds. TrAC Trends Anal. Chem. 2016, 77, 1-13. [CrossRef]

56. Jasinski, G.; Kalinowski, P.; Wozniak, L.; Koscinski, P.; Jasinski, P. An electronic nose based on the semiconducting and electrochemical gas sensors. In Proceedings of the 2017 21st European Microelectronics and Packaging Conference (EMPC) \& Exhibition, Warsaw, Poland, 10-13 September 2017; pp. 1-4.

57. Lin, H.; Jang, M.; Suslick, K.S. Preoxidation for Colorimetric Sensor Array Detection of VOCs. J. Am. Chem. Soc. 2011, 133, 16786-16789. [CrossRef]

58. Pádua, A.C.; Palma, S.; Gruber, J.; Gamboa, H.; Roque, A.C. Design and evolution of an opto-electronic device for vocs detection. Biomed. Eng. Syst. Technol. Int. Jt. Conf. BIOSTEC Revis. Sel. Pap. 2018, 1, 48-55. [PubMed]

59. Kladsomboon, S.; Lutz, M.; Pogfay, T.; Puntheeranurak, T.; Kerdcharoen, T. Hybrid optical-electrochemical electronic nose system based on Zn-porphyrin and multi-walled carbon nanotube composite. J. Nanosci. Nanotechnol. 2012, 12, 5240-5244. [CrossRef] [PubMed]

60. Thepudom, T.; Kladsomboon, S.; Pogfay, T.; Tuantranont, A.; Kerdcharoen, T. Portable optical-based electronic nose using dual-sensors array applied for volatile discrimination. In Proceedings of the 20129 th International Conference on Electrical Engineering/Electronics, Computer, Telecommunications and Information Technology, Phetchaburi, Thailand, 16-18 May 2012; pp. 1-4.

61. Wang, D.; Wang, L.; Yu, J.; Wang, P.; Hu, Y.; Ying, K. Characterization of a modified surface acoustic wave sensor used in electronic nose for potential application in breath diagnosis. Sens. Lett. 2011, 9, 884-889. [CrossRef]

62. Zhao, Y.; Yang, Q.; Chang, Y.; Qu, H.; Pang, W.; Zhang, H.; Duan, X. Detection and discrimination of volatile organic compounds using a single multi-resonance mode piezotransduced silicon bulk acoustic wave resonator (PSBAR) as virtual sensor array. Sens. Actuators B Chem. 2018, 254, 1191-1199. [CrossRef]

63. Wong, Y.C.; Ang, B.C.; Haseeb, A.; Baharuddin, A.A.; Wong, Y.H. Conducting polymers as chemiresistive gas sensing materials: A review. J. Electrochem. Soc. 2019, 167, 037503. [CrossRef]

64. Fanget, S.; Hentz, S.; Puget, P.; Arcamone, J.; Matheron, M.; Colinet, E.; Andreucci, P.; Duraffourg, L.; Myers, E.; Roukes, M. Gas sensors based on gravimetric detection-A review. Sens. Actuators B Chem. 2011, 160, 804-821. [CrossRef]

65. Ni, Y.; Kumagai, K.; Yanagisawa, Y. Measuring emissions of organophosphate flame retardants using a passive flux sampler. Atmos. Environ. 2007, 41, 3235-3240. [CrossRef]

66. Salthammer, T.; Fuhrmann, F.; Uhde, E. Flame retardants in the indoor environment-Part II: Release of VOCs (triethylphosphate and halogenated degradation products) from polyurethane. Indoor Air 2003, 13, 49-52. [CrossRef] 
67. Solbu, K.; Daae, H.L.; Olsen, R.; Thorud, S.; Ellingsen, D.G.; Lindgren, T.; Bakke, B.; Lundanes, E.; Molander, P. Organophosphates in aircraft cabin and cockpit air-method development and measurements of contaminants. J. Environ. Monit. 2011, 13, 1393-1403. [CrossRef] [PubMed]

68. Duberg, D. Identification of Volatile Organic Compounds (VOC) and Organophosphate Flame Retardants (OPFR) in Building Materials; Örebro University: Örebro, Sweden, 2017.

69. Shin, H.-M.; McKone, T.E.; Bennett, D.H. Volatilization of low vapor pressure-Volatile organic compounds (LVP-VOCs) during three cleaning products-associated activities: Potential contributions to ozone formation. Chemosphere 2016, 153, 130-137. [CrossRef]

70. Steinemann, A. Volatile emissions from common consumer products. Air Qual. Atmos. Health 2015, 8, 273-281. [CrossRef]

71. Dinh, T.-V.; Kim, S.-Y.; Son, Y.-S.; Choi, I.-Y.; Park, S.-R.; Sunwoo, Y.; Kim, J.-C. Emission characteristics of VOCs emitted from consumer and commercial products and their ozone formation potential. Environ. Sci. Pollut. Res. 2015, 22, 9345-9355. [CrossRef]

72. Loh, M.M.; Houseman, E.A.; Gray, G.M.; Levy, J.I.; Spengler, J.D.; Bennett, D.H. Measured Concentrations of VOCs in Several Non-Residential Microenvironments in the United States. Environ. Sci. Technol. 2006, 40, 6903-6911. [CrossRef] [PubMed]

73. Hashemipour, S.; Yaftian, M.R.; Kalhor, H.; Ghanbari, M. A study on the discrimination of xylene isomers vapors by quartz crystal microbalance sensors. J. Iran. Chem. Soc. 2021, 18, 751-763. [CrossRef]

74. Goettler, L.A.; Scobbo, J.J. Applications of Polymer Blends. In Polymer Blends Handbook; Utracki, L.A., Wilkie, C.A., Eds.; Springer: Dordrecht, The Netherlands, 2014; pp. 1433-1458. [CrossRef]

75. Curry, J.E. Practical aspects of processing of blends. In Polymer Blends and Alloys; Folkes, M.J., Hope, P.S., Eds.; Springer: Dordrecht, The Netherlands, 1993; pp. 7-45. [CrossRef]

76. Habuka, H.; Ono, N.; Sakurai, A.; Naito, T. Molecular adsorption and desorption behavior on silicon surface in a complex ambient atmosphere containing vapors of Diethylphthalate, acetic acid and water. Am. J. Anal. Chem. 2013, 4, 34442. [CrossRef]

77. Habuka, H.; Tawada, M.; Takeuchi, T.; Aihara, M. Gas Velocity Influence on Silicon Surface Organic Contamination Evaluated Using Quartz Crystal Microbalance. J. Electrochem. Soc. 2005, 152, G862. [CrossRef]

78. Hori, K.; Zhou, Y.; Kanai, T.; Habuka, H. Temperature Influence on Organic Molecular Interaction on Silicon Oxide Surface In Situ Measured Utilizing a Quartz Crystal Microbalance. ECS J. Solid State Sci. Technol. 2020, 9, 104007. [CrossRef]

79. Habuka, H.; Yamaya, D. In-Situ Measurement Method and Rate Theory for Clarifying Multi-Component Organic Compounds Adsorption and Desorption on Silicon Surface. ECS Trans. 2007, 11, 363. [CrossRef]

80. Curie, J.; Curie, P. An oscillating quartz crystal mass detector. Rendu 1880, 91, 294-297.

81. Sauerbrey, G.Z. Use of quartz vibrator for weighting thin films on a microbalance. Z. Phys. 1959, 155, 206-212. [CrossRef]

82. Johannsmann, D. The quartz crystal microbalance in soft matter research. In Soft and Biological Matter; Springer: Berlin/Heidelberg, Germany, 2015; pp. 191-204.

83. DeNolf, G.C.; Haack, L.; Holubka, J.; Straccia, A.; Blohowiak, K.; Broadbent, C.; Shull, K.R. High frequency rheometry of viscoelastic coatings with the quartz crystal microbalance. Langmuir 2011, 27, 9873-9879. [CrossRef]

84. Speller, N.C.; Siraj, N.; Regmi, B.P.; Marzoughi, H.; Neal, C.; Warner, I.M. Rational Design of QCM-D Virtual Sensor Arrays Based on Film Thickness, Viscoelasticity, and Harmonics for Vapor Discrimination. Anal. Chem. 2015, 87, 5156-5166. [CrossRef]

85. Vaughan, S.R.; Pérez, R.L.; Chhotaray, P.; Warner, I.M. Quartz Crystal Microbalance Based Sensor Arrays for Detection and Discrimination of VOCs Using Phosphonium Ionic Liquid Composites. Sensors 2020, 20, 615. [CrossRef] [PubMed]

86. Vaughan, S.R.; Speller, N.C.; Chhotaray, P.; McCarter, K.S.; Siraj, N.; Pérez, R.L.; Li, Y.; Warner, I.M. Class specific discrimination of volatile organic compounds using a quartz crystal microbalance based multisensor array. Talanta 2018, 188, 423-428. [CrossRef] [PubMed]

87. Fan, X.; Du, B. Selective detection of trace p-xylene by polymer-coated QCM sensors. Sens. Actuators B Chem. 2012, 166-167, 753-760. [CrossRef]

88. Fan, X.; Du, B. Selective detection of trace 1-butanol by QCM sensor coated with copolymer P(HEMA-co-MA). Sens. Actuators B Chem. 2011, 160, 724-729. [CrossRef]

89. Rianjanu, A.; Triyana, K.; Nugroho, D.B.; Kusumaatmaja, A.; Roto, R. Electrospun polyvinyl acetate nanofiber modified quartz crystal microbalance for detection of primary alcohol vapor. Sens. Actuators A Phys. 2020, 301, 111742. [CrossRef]

90. Rianjanu, A.; Nugroho, D.B.; Kusumaatmaja, A.; Roto, R.; Triyana, K. A study of quartz crystal microbalance modified with polyvinyl acetate nanofiber to differentiate short-chain alcohol isomers. Sens. Bio-Sens. Res. 2019, 25, 100294. [CrossRef]

91. Rianjanu, A.; Nurfani, E.; Arif, M.F.; Triyana, K.; Wasisto, H.S. Stability evaluation of quartz crystal microbalances coated with polyvinyl acetate nanofibrous mats as butanol vapor sensors. Mater. Today Commun. 2020, 101770. [CrossRef]

92. Rianjanu, A.; Hasanah, S.A.; Nugroho, D.B.; Kusumaatmaja, A.; Roto, R.; Triyana, K. Polyvinyl Acetate Film-Based Quartz Crystal Microbalance for the Detection of Benzene, Toluene, and Xylene Vapors in Air. Chemosensors 2019, 7, 20. [CrossRef]

93. Triyana, K.; Rianjanu, A.; Nugroho, D.B.; As'ari, A.H.; Kusumaatmaja, A.; Roto, R.; Suryana, R.; Wasisto, H.S. A highly sensitive safrole sensor based on polyvinyl acetate (PVAc) nanofiber-coated QCM. Sci. Rep. 2019, 9, 15407. [CrossRef] [PubMed]

94. Roto, R.; Rianjanu, A.; Fatyadi, I.A.; Kusumaatmaja, A.; Triyana, K. Enhanced sensitivity and selectivity of ammonia sensing by QCM modified with boric acid-doped PVAc nanofiber. Sens. Actuators A Phys. 2020, 304, 111902. [CrossRef]

95. Roto, R.; Rianjanu, A.; Rahmawati, A.; Fatyadi, I.A.; Yulianto, N.; Majid, N.; Syamsu, I.; Wasisto, H.S.; Triyana, K. Quartz Crystal Microbalances Functionalized with Citric Acid-Doped Polyvinyl Acetate Nanofibers for Ammonia Sensing. ACS Appl. Nano Mater. 2020, 3, 5687-5697. [CrossRef] 
96. Scott, A.J.; Majdabadifarahani, N.; Stewart, K.M.E.; Duever, T.A.; Penlidis, A. Straightforward Synthesis and Evaluation of Polymeric Sensing Materials for Acetone Detection. Macromol. React. Eng. 2020, 14, 2000004. [CrossRef]

97. Ayad, M.M.; Salahuddin, N.A.; Minisy, I.M.; Amer, W.A. Chitosan/polyaniline nanofibers coating on the quartz crystal microbalance electrode for gas sensing. Sens. Actuators B Chem. 2014, 202, 144-153. [CrossRef]

98. Triyana, K.S.A.; Rianjanu, A.; Hidayat, S.N.; Riowirawan, R.; Julian, T.; Kusumaatmaja, A.; Santoso, I.; Roto, R. Chitosan-Based Quartz Crystal Microbalance for Alcohol Sensing. Electronics 2018, 7, 181. [CrossRef]

99. Das, R.; Bandyopadhyay, R.; Pramanik, P. Stereo-regulated Schiff base siloxane polymer coated QCM sensor for amine vapor detection. Mater. Chem. Phys. 2019, 226, 214-219. [CrossRef]

100. Humairah, N.A.; Fadlunisa, F.; Histhiningtyas, K.A.; Fatyadi, I.A.; Roto, R.; Kusumaatmaja, A.; Triyana, K. Molecular Imprinting Polymer-Based QCM Sensor for Detection of $\alpha$-Pinene. Key Eng. Mater. 2020, 840, 418-423. [CrossRef]

101. Matsuguchi, M.; Uno, T. Molecular imprinting strategy for solvent molecules and its application for QCM-based VOC vapor sensing. Sens. Actuators B Chem. 2006, 113, 94-99. [CrossRef]

102. Hussain, M.; Kotova, K.; Lieberzeit, P.A. Molecularly imprinted polymer nanoparticles for formaldehyde sensing with QCM. Sensors 2016, 16, 1011. [CrossRef]

103. Hwang, M.-J.; Shim, W.-G.; Yoon, S.-D.; Moon, H. Adsorption of toxic gases on molecularly imprinted polymer coated QCM: Measurements and modeling for partial pressure in gas mixture. Adsorption 2019, 25, 825-832. [CrossRef]

104. Chen, W.; Wang, Z.; Gu, S.; Wang, J. Detection of hexanal in humid circumstances using hydrophobic molecularly imprinted polymers composite. Sens. Actuators B Chem. 2019, 291, 141-147. [CrossRef]

105. Banerjee, M.B.; Pradhan, S.; Roy, R.B.; Tudu, B.; Das, D.K.; Bandyopadhyay, R.; Pramanik, P. Detection of Benzene and Volatile Aromatic Compounds by Molecularly Imprinted Polymer-Coated Quartz Crystal Microbalance Sensor. IEEE Sens. J. 2019, 19, 885-892. [CrossRef]

106. Lu, H.-L.; Lu, C.-J.; Tian, W.-C.; Sheen, H.-J. A vapor response mechanism study of surface-modified single-walled carbon nanotubes coated chemiresistors and quartz crystal microbalance sensor arrays. Talanta 2015, 131, 467-474. [CrossRef]

107. Consales, M.; Campopiano, S.; Cutolo, A.; Penza, M.; Aversa, P.; Cassano, G.; Giordano, M.; Cusano, A. Carbon nanotubes thin films fiber optic and acoustic VOCs sensors: Performances analysis. Sens. Actuators B Chem. 2006, 118, 232-242. [CrossRef]

108. Mañoso, E.; Herrera-Basurto, R.; Simonet, B.; Valcárcel, M. A quartz crystal microbalance modified with carbon nanotubes as a sensor for volatile organic compounds. Sens. Actuators B Chem. 2013, 186, 811-816. [CrossRef]

109. Quang, V.V.; Hung, V.N.; Tuan, L.A.; Phan, V.N.; Huy, T.Q.; Quy, N.V. Graphene-coated quartz crystal microbalance for detection of volatile organic compounds at room temperature. Thin Solid Film. 2014, 568, 6-12. [CrossRef]

110. Zhang, K.; Hu, R.; Fan, G.; Li, G. Graphene oxide/chitosan nanocomposite coated quartz crystal microbalance sensor for detection of amine vapors. Sens. Actuators B Chem. 2017, 243, 721-730. [CrossRef]

111. Zhao, Q.; He, Z.; Jiang, Y.; Yuan, Z.; Wu, H.; Su, C.; Tai, H. Enhanced acetone-sensing properties of PEI thin film by GO-NH2 functional groups modification at room temperature. Front. Mater. 2019, 5, 82. [CrossRef]

112. Van Cat, V.; Dinh, N.X.; Phan, V.N.; Le, A.T.; Nam, M.H.; Lam, V.D.; Van Dang, T.; Van Quy, N. Realization of graphene oxide nanosheets as a potential mass-type gas sensor for detecting NO2, SO2, CO, and NH3. Mater. Today Commun. 2020, $25,101682$. [CrossRef]

113. Büyükkabasakal, K.; Acikbas, S.C.; Deniz, A.; Acikbas, Y.; Capan, R.; Erdogan, M. Chemical Sensor Properties and Mathematical Modeling of Graphene Oxide Langmuir-Blodgett Thin Films. IEEE Sens. J. 2019, 19, 9097-9104. [CrossRef]

114. Xu, X.; Li, C.; Pei, K.; Zhao, K.; Zhao, Z.K.; Li, H. Ionic liquids used as QCM coating materials for the detection of alcohols. Sens. Actuators B Chem. 2008, 134, 258-265. [CrossRef]

115. Liang, C.; Yuan, C.-Y.; Warmack, R.J.; Barnes, C.E.; Dai, S. Ionic liquids: A new class of sensing materials for detection of organic vapors based on the use of a quartz crystal microbalance. Anal. Chem. 2002, 74, 2172-2176. [CrossRef] [PubMed]

116. Serrano-Santos, M.B.; Llobet, E.; Schäfer, T. Quartz crystal microbalance with dissipation measurement for proving the potential of ionic liquids as selective sensing Materials. Procedia Eng. 2011, 25, 1169-1172. [CrossRef]

117. Rehman, A.; Zeng, X. Methods and approaches of utilizing ionic liquids as gas sensing materials. RSC Adv. 2015, 5, 58371-58392. [CrossRef] [PubMed]

118. Chang, Y.-P.; Liu, W.-C.; Tseng, M.-C.; Chu, Y.-H. Ionic liquids tailored for reaction-based gas sensing on quartz crystal microbalance. Rev. Anal. Chem. 2015, 34, 77-86. [CrossRef]

119. Warner, I.M.; El-Zahab, B.; Siraj, N. Perspectives on Moving Ionic Liquid Chemistry into the Solid Phase. Anal. Chem. 2014, 86, 7184-7191. [CrossRef] [PubMed]

120. Tseng, M.-C.; Chu, Y.-H. Chemoselective gas sensing ionic liquids. Chem. Commun. 2010, 46, 2983-2985. [CrossRef]

121. Liu, Y.-L.; Tseng, M.-C.; Chu, Y.-H. Sensing ionic liquids for chemoselective detection of acyclic and cyclic ketone gases. Chem. Commun. 2013, 49, 2560-2562. [CrossRef] [PubMed]

122. Li, H.-Y.; Chu, Y.-H. Exploiting solvate ionic liquids for amine gas analysis on a quartz crystal microbalance. Anal. Chem. 2017, 89, 5186-5192. [CrossRef]

123. Chen, C.-Y.; Li, K.-H.; Chu, Y.-H. Reaction-based detection of chemical warfare agent mimics with affinity ionic liquids. Anal. Chem. 2018, 90, 8320-8325. [CrossRef] [PubMed] 
124. Regmi, B.P.; Speller, N.C.; Anderson, M.J.; Brutus, J.O.; Merid, Y.; Das, S.; El-Zahab, B.; Hayes, D.J.; Murray, K.K.; Warner, I.M. Molecular weight sensing properties of ionic liquid-polymer composite films: Theory and experiment. J. Mater. Chem. C 2014, 2, 4867-4878. [CrossRef]

125. Speller, N.C.; Siraj, N.; McCarter, K.S.; Vaughan, S.; Warner, I.M. QCM virtual sensor array: Vapor identification and molecular weight approximation. Sens. Actuators B Chem. 2017, 246, 952-960. [CrossRef]

126. Speller, N.C.; Siraj, N.; Vaughan, S.; Speller, L.N.; Warner, I.M. QCM virtual multisensor array for fuel discrimination and detection of gasoline adulteration. Fuel 2017, 199, 38-46. [CrossRef]

127. Speller, N.C.; Siraj, N.; Vaughan, S.; Speller, L.N.; Warner, I.M. Assessment of QCM array schemes for mixture identification: Citrus scented odors. RSC Adv. 2016, 6, 95378-95386. [CrossRef]

128. Aleixandre, M.; Nakamoto, T. Study of Room Temperature Ionic Liquids as Gas Sensing Materials in Quartz Crystal Microbalances. Sensors 2020, 20, 4026. [CrossRef] [PubMed]

129. Li, D.; Ma, M. Surface acoustic wave microsensors based on cyclodextrin coatings. Sens. Actuators B Chem. 2000, 69, 75-84. [CrossRef]

130. Ju, J.-F.; Syu, M.-J.; Teng, H.-S.; Chou, S.-K.; Chang, Y.-S. Preparation and identification of $\beta$-cyclodextrin polymer thin film for quartz crystal microbalance sensing of benzene, toluene, and p-xylene. Sens. Actuators B Chem. 2008, 132, 319-326. [CrossRef]

131. McGinn, C.K.; Lamport, Z.A.; Kymissis, I. Review of Gravimetric Sensing of Volatile Organic Compounds. ACS Sens. 2020, 5 , 1514-1534. [CrossRef] [PubMed]

132. Temel, F. One novel calix [4] arene based QCM sensor for sensitive, selective and high performance-sensing of formaldehyde at room temperature. Talanta 2020, 211, 120725. [CrossRef] [PubMed]

133. Temel, F.; Ozcelik, E.; Ture, A.G.; Tabakci, M. Sensing abilities of functionalized calix[4]arene coated QCM sensors towards volatile organic compounds in aqueous media. Appl. Surf. Sci. 2017, 412, 238-251. [CrossRef]

134. Temel, F.; Tabakci, M. Calix [4] arene coated QCM sensors for detection of VOC emissions: Methylene chloride sensing studies. Talanta 2016, 153, 221-227. [CrossRef] [PubMed]

135. Halay, E.; Acikbas, Y.; Capan, R.; Bozkurt, S.; Erdogan, M.; Unal, R. A novel triazine-bearing calix[4]arene: Design, synthesis and gas sensing affinity for volatile organic compounds. Tetrahedron 2019, 75, 2521-2528. [CrossRef]

136. Sasaki, K.; Furusawa, H.; Nagamine, K.; Tokito, S. Detection of Odorant Molecules in the Gaseous Phase Using $\alpha-$, $\beta-$, and $\gamma$-Cyclodextrin Films on a Quartz Crystal Microbalance. Technologies 2018, 6, 63. [CrossRef]

137. Martin, S.J.; Granstaff, V.E.; Frye, G.C. Characterization of a quartz crystal microbalance with simultaneous mass and liquid loading. Anal. Chem. 1991, 63, 2272-2281. [CrossRef]

138. Arnau, A. A Review of Interface Electronic Systems for AT-cut Quartz Crystal Microbalance Applications in Liquids. Sensors 2008, 8, 370-411. [CrossRef]

139. Schröder, J.; Borngräber, R.; Lucklum, R.; Hauptmann, P. Network analysis based interface electronics for quartz crystal microbalance. Rev. Sci. Instrum. 2001, 72, 2750-2755. [CrossRef]

140. Calvo, E.; Etchenique, R.; Bartlett, P.N.; Singhal, K.; Santamaria, C. Quartz crystal impedance studies at $10 \mathrm{MHz}$ of viscoelastic liquids and films. Faraday Discuss. 1997, 107, 141-157. [CrossRef]

141. Kankare, J.; Loikas, K.; Salomäki, M. Method for Measuring the Losses and Loading of a Quartz Crystal Microbalance. Anal. Chem. 2006, 78, 1875-1882. [CrossRef]

142. Wudy, F.; Multerer, M.; Stock, C.; Schmeer, G.; Gores, H. Rapid impedance scanning QCM for electrochemical applications based on miniaturized hardware and high-performance curve fitting. Electrochim. Acta 2008, 53, 6568-6574. [CrossRef]

143. Mills, C.; Chai, K.; Milgrew, M.; Glidle, A.; Cooper, J.; Cumming, D. A Multiplexed Impedance Analyzer for Characterizing Polymer-Coated QCM Sensor Arrays. IEEE Sens. J. 2006, 6, 996-1002. [CrossRef]

144. Dixon, M.C. Quartz Crystal Microbalance with Dissipation Monitoring: Enabling Real-Time Characterization of Biological Materials and Their Interactions. J. Biomol. Tech. JBT 2008, 19, 151-158.

145. Rodahl, M.; Höök, F.; Kasemo, B. QCM operation in liquids: An explanation of measured variations in frequency and Q factor with liquid conductivity. Anal. Chem. 1996, 68, 2219-2227. [CrossRef] [PubMed]

146. Baù, M.; Ferrari, M.; Ferrari, V. Analysis and Validation of Contactless Time-Gated Interrogation Technique for Quartz Resonator Sensors. Sensors 2017, 17, 1264. [CrossRef] [PubMed]

147. Ferrari, M.; Bau', M.; Pagnoni, M.; Ferrari, V. Compact DDS-based system for contactless interrogation of resonant sensors based on time-gated technique. In IEEE SENSORS 2014 Proceedings; Institute of Electrical and Electronics Engineers (IEEE): New York City, NY, USA, 2014; pp. 907-910.

148. Eichelbaum, F.; Borngräber, R.; Schröder, J.; Lucklum, R.; Hauptmann, P. Interface circuits for quartz-crystal-microbalance sensors. Rev. Sci. Instrum. 1999, 70, 2537-2545. [CrossRef]

149. Borngräber, R.; Schröder, J.; Lucklum, R.; Hauptmann, P. Is an oscillator-based measurement adequate in a liquid environment? IEEE Trans. Ultrason. Ferroelectr. Freq. Control 2002, 49, 1254-1259. [CrossRef] [PubMed]

150. Beeley, J.; Mills, C.; Hammond, P.; Glidle, A.; Cooper, J.; Wang, L.; Cumming, D. All-digital interface ASIC for a QCM-based electronic nose. Sens. Actuators B Chem. 2004, 103, 31-36. [CrossRef]

151. Syahbana, M.A.; Santjojo, D.J.H.D.; Sakti, S.P. High-resolution multiple channel frequency counter using spartan-3E FPGA. In Proceedings of the 2016 International Seminar on Sensors, Instrumentation, Measurement and Metrology (ISSIMM), Malang, Indonesia, 10-11 August 2016; pp. 111-114. [CrossRef] 
152. Molanes, R.F.; Fariña, J.; Rodríguez-Andina, J.J. Field-Programmable System-on-Chip for high-accuracy frequency measurements in QCM sensors. In Proceedings of the IECON 2013-39th Annual Conference of the IEEE Industrial Electronics Society, Vienna, Austria, 10-13 November 2013.

153. Torres, R.; Arnau, A.; Perrot, H.; Aedo, J.E. Electronic system for experimentation in AC Electrogravimetry II: Implemented design. Rev. EIA 2007, 7, 63-73.

154. Torres, R.; García, J.V.; Arnau, A.; Perrot, H.; Kim, L.T.T.; Gabrielli, C. Improved frequency/voltage converters for fast quartz crystal microbalance applications. Rev. Sci. Instrum. 2008, 79, 45113. [CrossRef]

155. Hampitak, P.; Jowitt, T.A.; Melendrez, D.; Fresquet, M.; Hamilton, P.; Iliut, M.; Nie, K.; Spencer, B.; Lennon, R.; Vijayaraghavan, A. A Point-of-Care Immunosensor Based on a Quartz Crystal Microbalance with Graphene Biointerface for Antibody Assay. ACS Sens. 2020, 5, 3520-3532. [CrossRef] [PubMed]

156. Turkdogan, S. Bandgap engineered II-VI quaternary alloys and their humidity sensing performance analyzed by QCM. J. Mater. Sci. Mater. Electron. 2019, 30, 10427-10434. [CrossRef]

157. Okur, S.; Zhang, Z.; Sarheed, M.; Nick, P.; Lemmer, U.; Heinke, L. Towards a MOF e-Nose: A SURMOF sensor array for detection and discrimination of plant oil scents and their mixtures. Sens. Actuators B Chem. 2020, 306, 127502. [CrossRef] 